\title{
Dynamic testing of a four-storey building with reinforced concrete and unreinforced masonry walls: prediction, test results and data set
}

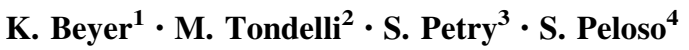

Received: 5 September 2014/ Accepted: 18 March 2015

(C) Springer Science+Business Media Dordrecht 2015

\begin{abstract}
This paper presents the results of a series of shake-table tests on a half-scale, four-storey building with reinforced concrete and unreinforced masonry walls. Due to the lack of reference tests, the seismic behaviour of such mixed structures is poorly understood. The test unit was subjected to several runs of increasing intensity yielding performance states between minor damage and near collapse. Before the test, the expected peak table accelerations leading to different limit states were estimated using the capacity spectrum method, and the predicted values corresponded rather well to actual sustained accelerations. Next to these analyses, the paper describes the test unit, instrumentation and input motion, and comments on the response of the mixed structure in terms of damage evolution and global response quantities, such as force-displacement response and drift and acceleration profiles. The raw and post-processed data sets are made publically available, and all relevant information with regard to data organisation and post-processing procedure is described in an appendix to this paper. The test serves therefore as a benchmark for the validation of numerical models of such mixed structures. The project aims at providing a foundation for the development of seismic design and assessment methods of mixed structures, which are currently not covered by structural codes, including Eurocode 8 .
\end{abstract}

K. Beyer

katrin.beyer@epfl.ch

1 Earthquake Engineering and Structural Dynamics Laboratory (EESD), School of Architecture, Civil and Environmental Engineering (ENAC), École Polytechnique Fédérale de Lausanne (EPFL), EPFL ENAC IIC EESD, GC B2 504, Station 18, 1015 Lausanne, Switzerland

2 Earthquake Engineering and Structural Dynamics Laboratory (EESD), School of Architecture, Civil and Environmental Engineering (ENAC), École Polytechnique Fédérale de Lausanne (EPFL), EPFL ENAC IIC EESD, GC B2 484, Station 18, 1015 Lausanne, Switzerland

3 Earthquake Engineering and Structural Dynamics Laboratory (EESD), School of Architecture, Civil and Environmental Engineering (ENAC), École Polytechnique Fédérale de Lausanne (EPFL), EPFL ENAC IIC EESD, GC B2 495, Station 18, 1015 Lausanne, Switzerland

4 European Centre for Training and Research in Earthquake Engineering (EUCENTRE), Via Ferrata 1, 27100 Pavia, Italy 
Keywords Shake-table test · Unreinforced masonry wall - Reinforced concrete wall · Mixed structure

\section{Introduction}

The recently completed European research project SHARE, which aimed at harmonising the seismic hazard maps of Europe, reveals that countries of low to moderate seismic hazard in stable continental regions have higher spectral values than previous studies showed (Giardini and Wössner 2012). Once these new insights are reflected in seismic hazard maps of European building codes, the seismic performance of a large number of existing buildings will need to be reassessed. Among the most vulnerable structures are unreinforced masonry (URM) structures. URM structures that do not satisfy the seismic design check are often reinforced by adding reinforced concrete (RC) walls or replacing selected URM walls by RC walls. In some countries of moderate seismic hazard, such as Switzerland, new residential buildings of three to six stories are already today conceived as mixed structures with RC and URM walls. In typical building configurations, the URM walls outnumber the RC walls. The RC walls often accommodate stair cases or lift shafts and are therefore also often situated at the perimeter of the building. Examples of new and existing buildings with URM and RC walls are shown in Figs. 1, 2.
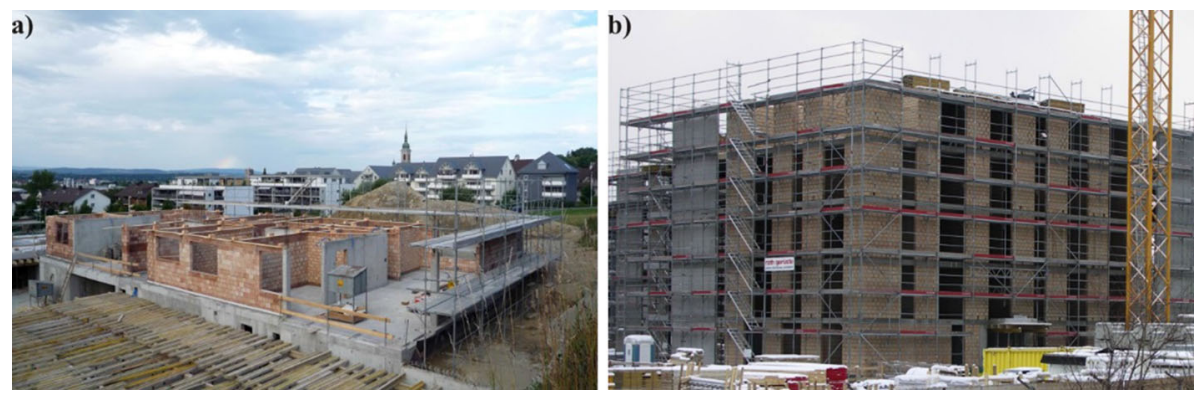

Fig. 1 Examples of new buildings with RC and URM walls in Switzerland (Photos: Thomas Wenk)
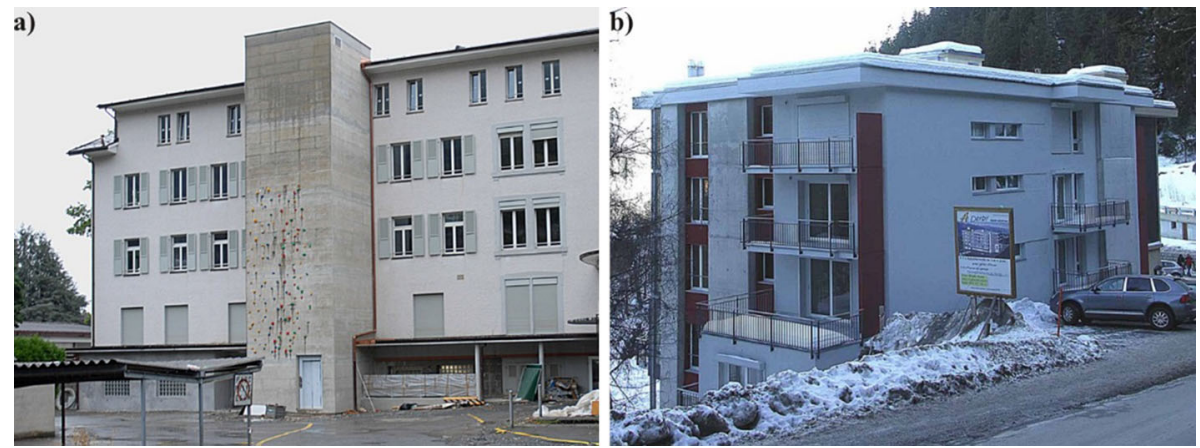

Fig. 2 Examples of existing URM buildings retrofitted with RC walls in Switzerland (Photos: Thomas Wenk) 
Although structures with URM and RC walls are therefore rather common, current seismic design and assessment codes, including Eurocode 8 (CEN 2004b, 2005), do not address such mixed structures. The development of guidelines is hindered by a lack of knowledge on the interaction of the two types of structural elements. In addition, the analysis results are rather sensitive to several modelling assumptions, such as assumed cracked member stiffnesses and effective widths of RC slabs (Paparo and Beyer 2014). Validation of numerical models proved difficult, since experimental evidence on structures with URM and RC walls was limited. In a shake-table test of a three-storey building with URM walls and one central RC column (Tomaževič et al. 1990), the latter had no influence on the global response of the building up to near collapse, since the URM walls were considerably stiffer than the RC column. The most similar system tested was a four-storey building with URM walls and a RC frame at the ground floor. URM walls were found at the top floors, the structure of which was strengthened by adding a RC wall placed onto a rubber plate that was fixed to the foundation (Jurukovski et al. 1992). Due to this rubber plate as well as the RC frame at the ground floor, this test unit does not, however, represent the type of construction investigated here (Figs. 1, 2).

To improve the understanding of structures with URM and RC walls, a research initiative was started at EPFL (Lausanne, Switzerland), which included next to the shaketable test described in this paper also quasi-static cyclic testing of two-storey structures featuring one RC wall and one URM wall that were coupled by RC slabs (Paparo and Beyer 2014). The shake-table test was a joint project with partners from Germany, Turkey and Switzerland and was carried out at the TREES laboratory of the European Centre for Training and Research in Earthquake Engineering (EUCENTRE) in Pavia, Italy within the scope of a SERIES grant of the FP7 programme. It consisted of uni-directional dynamic testing of a four-storey building with RC and URM walls coupled by RC slabs, which was constructed at half-scale. The structure represented a modern engineered residential building and is particularly typical of the construction practice of regions of low to moderate seismicity in Europe. The test unit was not designed according to a specific structural design code but with the objective of maximising the potential insights to be obtained from the tests, while respecting the boundaries of the testing facility. The objective of this shake-table test was to observe the behaviour of such mixed structures when subjected to seismic loading and to collect high-quality data that can be used for the validation of numerical models. The shake-table test was designed to address several open issues related to the seismic behaviour of mixed structures, as follows: drift and acceleration profiles over the height of the building, drift limits for different performance levels, evolution of damage and storey accelerations with increasing shaking intensity, and effective slab width and boundary conditions of out-of-plane loaded URM walls in such mixed structures. A particular focus is set on the different responses in the positive and negative direction of loading, which is typical for this type of structure, resulting from the grouping of the RC walls at one end of the building.

This paper presents the test unit and test programme (Sect. 2). The test unit was subjected to several runs of increasing intensity, covering performance levels between minor damage and near collapse. In Sect. 3, the damage evolution with increasing shaking intensity is discussed, and Sect. 4 presents test results for the global response (force-displacement response, drift and acceleration profiles) and the damage evolution (shift in periods, stiffnesses and storey response spectra). To predict the level of table accelerations that the structure could sustain, a pushover analysis of a shell element model of the test unit was performed, and the performance was assessed using the Capacity Spectrum Method. Section 5 presents the numerical results and compares them to the observed response. The 
appendix of this paper provides detailed information on the test unit's geometry and material properties. It also explains the organization of raw, processed and derived data for the nine runs, which is shared through the Web page www.zenodo.org (doi: 10.5281/ zenodo.11578).

\section{Test unit, test programme and instrumentation}

\subsection{Test unit}

The test unit represented a four-storey building with RC and URM walls at half-scale (Fig. 3). The artificial mass simulation law (Krawinkler 1979) was applied to account for the scaling. Hence, additional masses were provided in the form of unreinforced concrete blocks at each storey, and the time axis of the applied ground motion was divided by $\sqrt{ } 2$. The test unit was tested on a uni-directional shake-table, which direction of motion was aligned with the longitudinal axis of the structure (north-south axis). The two URM walls at the north and south end of the structure were loaded out-of-plane; the four URM walls and two RC walls of the east and west faced in-plane.

The test unit was symmetric along the north-south axis, thus avoiding a significant torsional component in its global response. With regard to the east-west axis, the structure was, however, asymmetric, since the URM walls that were loaded in-plane were grouped at the north end of the structure and the RC walls on the south end. This plan layout reflected the situation in real buildings where RC walls are typically not evenly distributed over the floor plan. The structure was regular over the height. At each storey, the walls were coupled by a RC slab and by masonry spandrels.

\subsection{Test programme and ground motion}

The input motion for the shake-table was the EW-component of the ground motion recorded at the Ulcinj-Hotel Albatros station during the April 15th, 1979 Montenegro earthquake from the European Strong-Motion Database (Ambraseys et al. 2002). The record was chosen for its broad frequency band. For the shake-table tests, the record was scaled to match peak ground accelerations (PGA) ranging from 0.05 to $0.9 \mathrm{~g}$. The PGA was increased from test to test; only for Test 7, the PGA was reduced with respect to the previous test in order to simulate the effect of an aftershock.
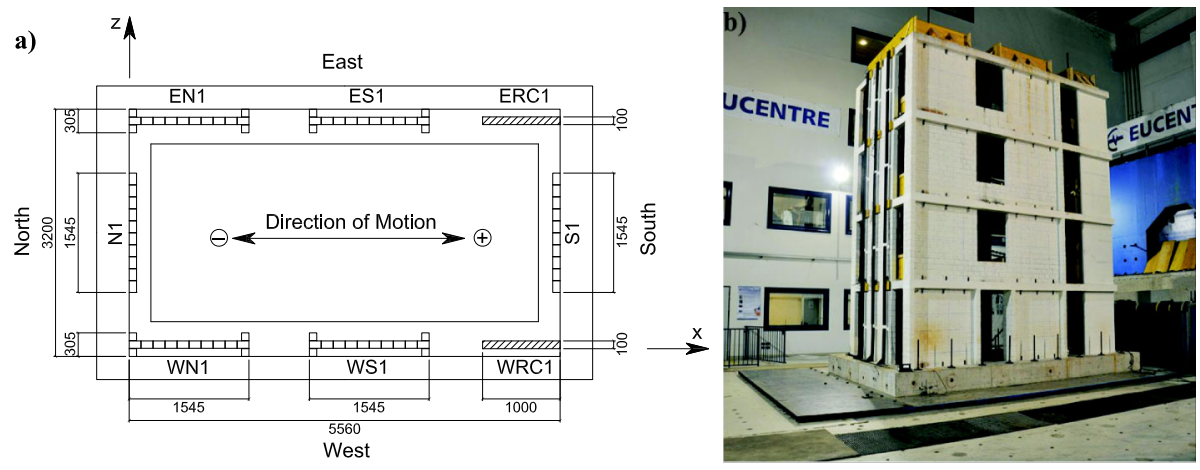

Fig. 3 Plan layout (dimensions in $\mathrm{mm}$ ) (a) and photo of test unit on shake-table (b) 
Table 1 Summary of the nominal and actual PGAs and EMS damage grades

\begin{tabular}{llll}
\hline Test number & Nominal PGA $(\mathrm{g})$ & Actual PGA $(\mathrm{g})$ & EMS damage grade \\
\hline 1 & 0.05 & 0.08 & DG1 \\
2 & 0.1 & 0.13 & DG1 \\
3 & 0.2 & 0.21 & DG1 \\
4 & 0.3 & 0.35 & DG2 \\
5 & 0.4 & 0.40 & DG2 \\
6 & 0.6 & 0.76 & DG2 \\
7 & 0.4 & 0.37 & DG2 \\
8 & 0.7 & 0.64 & DG3 \\
9 & 0.9 & 1.50 & DG4-5 \\
\hline
\end{tabular}
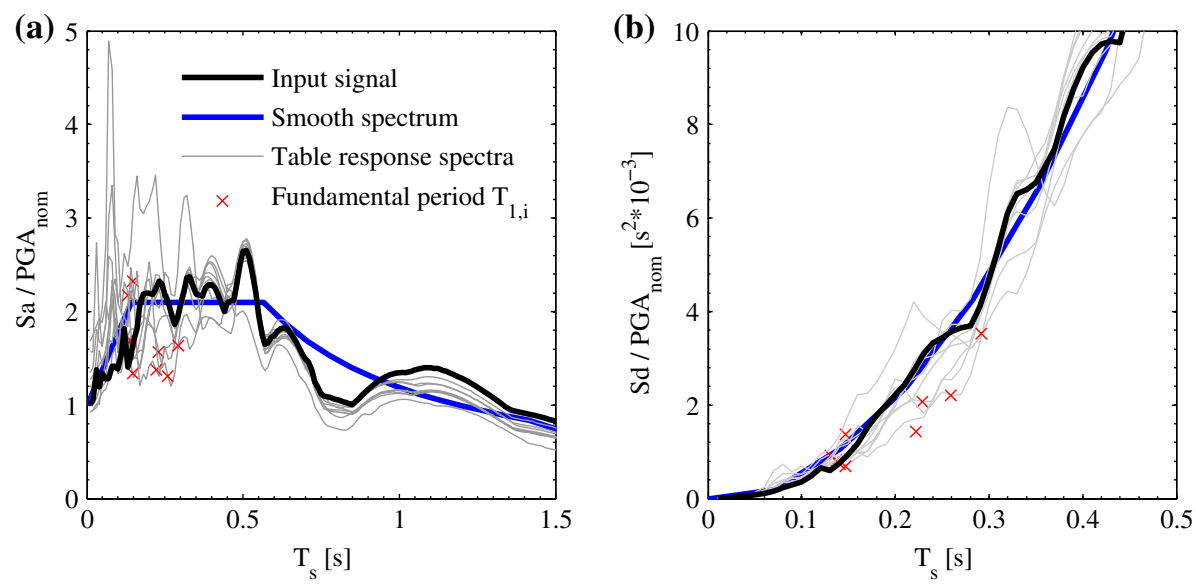

Fig. 4 Comparison of acceleration (a) and displacement (b) response spectra of input motion normalised with respect to the nominal PGA and smooth design spectrum used for the Capacity Spectrum Method

Due to feedback of the applied ground motion to the shake-table control, the movement of the shake-table never corresponds exactly to the input record; the difference increases with increasing nonlinearity in the response. Table 1 summarises the PGAs of the input signal (nominal PGAs) and the PGAs of the actual table movement (actual PGAs) of the nine runs. To indicate the state of the test unit after the run, a damage grade according to the European Macroseismic Scale (EMS, Grünthal 1998) is assigned. Figure 4 shows the acceleration and displacement response spectra of the nine runs normalized to the nominal PGA. In this plot, the spectral values at the fundamental period of the structure during each run are marked with a cross (for the evolution of the fundamental period see Sect. 4.2). As expected, the response spectra of the actual table acceleration differed most from the input signal around the fundamental period of the structure.

\subsection{Instrumentation}

The test unit was instrumented with 20 accelerometers, 49 displacement transducers and 24 omega gages. In addition to the conventional instruments, an optical measurement system 
recorded the in-plane displacements of 492 markers of the west façade of the URM walls and spandrels. Detailed information on the instrumentation can be found in the appendices of this paper, which also presents drawings of the test units, summarises the material properties and explains the organization of raw, processed and derived data for the nine runs. The data is publically available through the Web page www.zenodo.org and carries the doi: 10.5281/zenodo.11578.

\section{Test observations}

The test unit was subjected to nine runs with nominal peak ground accelerations between 0.05 and $0.90 \mathrm{~g}$, yielding performance levels between minor damage and near collapse. The damage evolution is described in Sect. 3.1 and the final failure mode in Sect. 3.2. These two sections are based on a test report which was written during the testing period (Tondelli et al. 2013).

\subsection{Damage evolution}

The first three tests, which featured nominal PGAs between $0.05 \mathrm{~g}$ and $0.2 \mathrm{~g}$, induced only very limited damage to the structure. After the first test $(0.05 \mathrm{~g})$, only one hairline crack in one of the URM walls of the first storey was observed. The second test $(0.1 \mathrm{~g})$ induced hairline cracks in the outer URM walls of the first and second storey (EN1/2 and WN1/2 walls) as well as in the construction joint between wall and foundation. The inner URM walls of the first storey (ES1 and WS1) developed first cracks during the third test $(0.2 \mathrm{~g})$. During this test, shear cracks in the outer URM walls grew in length and extended over almost the entire first storey. At the south end of the RC walls, several flexural cracks appeared up to a height of $0.35 \mathrm{~m}$ above the foundation. First flexural cracks in the firststorey slabs developed between the ERC wall and the ES wall.

After Tests $4(0.3 \mathrm{~g})$ and $5(0.4 \mathrm{~g})$, the inner URM walls of the first storey had developed several diagonal cracks over the entire wall height, but residual crack widths remained for all URM walls much less than $0.1-0.2 \mathrm{~mm}$ (Fig. 5). The slab of the first storey featured at this stage many flexural cracks; the average crack spacing was $20-40 \mathrm{~cm}$

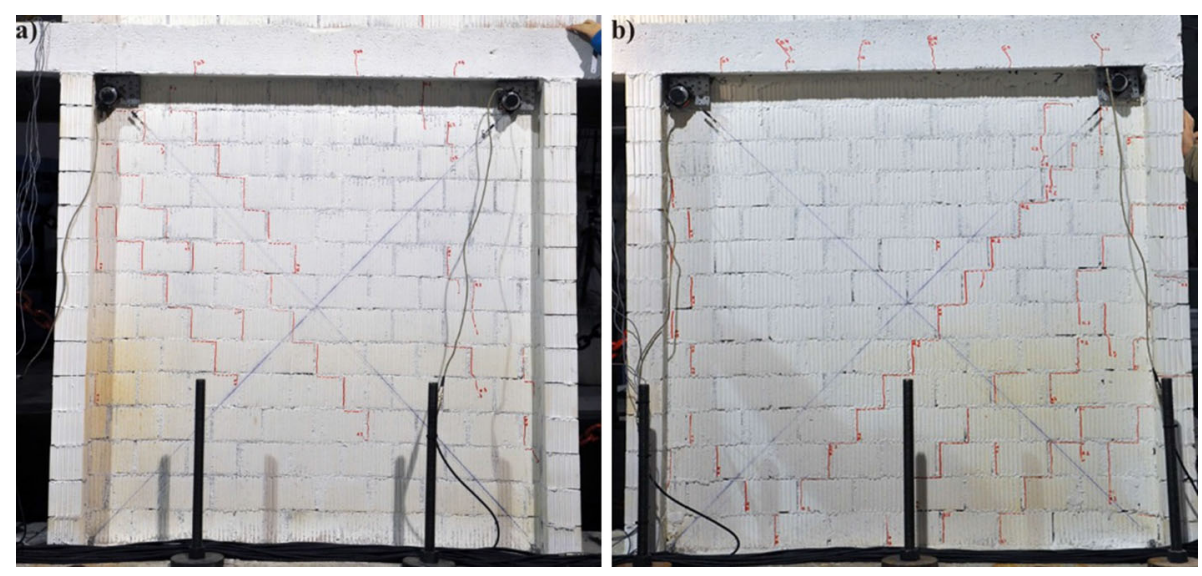

Fig. 5 PGA 0.4 g, first storey URM walls of east face: ES1 (a), EN1 (b) 

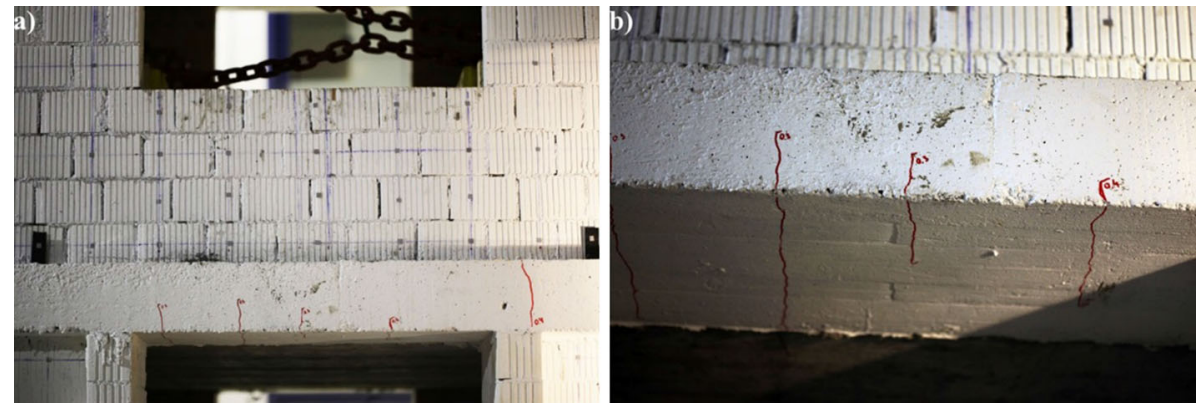

Fig. 6 PGA 0.4 g, cracks in slab spanning between both URM walls on the west face: side view (a) and bottom view (b)
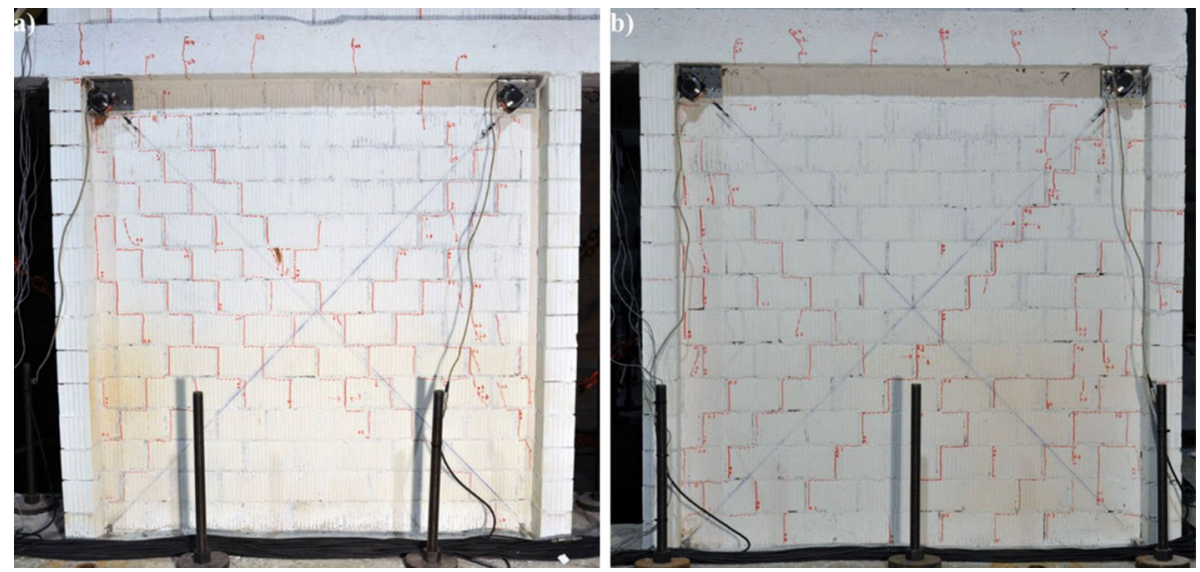

Fig. 7 Test $8(0.7 \mathrm{~g})$, first storey URM walls of East face: ES1 (a), EN1 (b)

(Fig. 6). However, the masonry spandrel above the slab as well as the RC slabs of the upper stories remained uncracked.

Test $6(0.6 \mathrm{~g})$ increased the damage to the structure significantly: At this point, all URM walls that were loaded in-plane developed diagonal cracks at all stories. At the first and second storey, maximum residual crack widths of $0.8 \mathrm{~mm}$ were measured; however, the majority of cracks had residual crack widths smaller than $0.2 \mathrm{~mm}$. In the third and fourth stories, the residual crack widths remained small (less than $0.1-0.2 \mathrm{~mm})$. Test $7(0.4 \mathrm{~g})$, performed with a lower level of intensity than Test 6 , simulated a possible aftershock but led only to very little additional damage, and the maximum residual crack widths remained practically unaltered.

After Test 8, the structure was severely damaged. At this point, the damage in the URM panels started concentrating in one diagonal crack (Fig. 7). From quasi-static cyclic tests on URM walls, it is known that this indicates that the post-peak branch has been reached, and failure is rather imminent (Petry and Beyer 2014b). In addition, diagonal cracks now passed for the first time through bricks. 

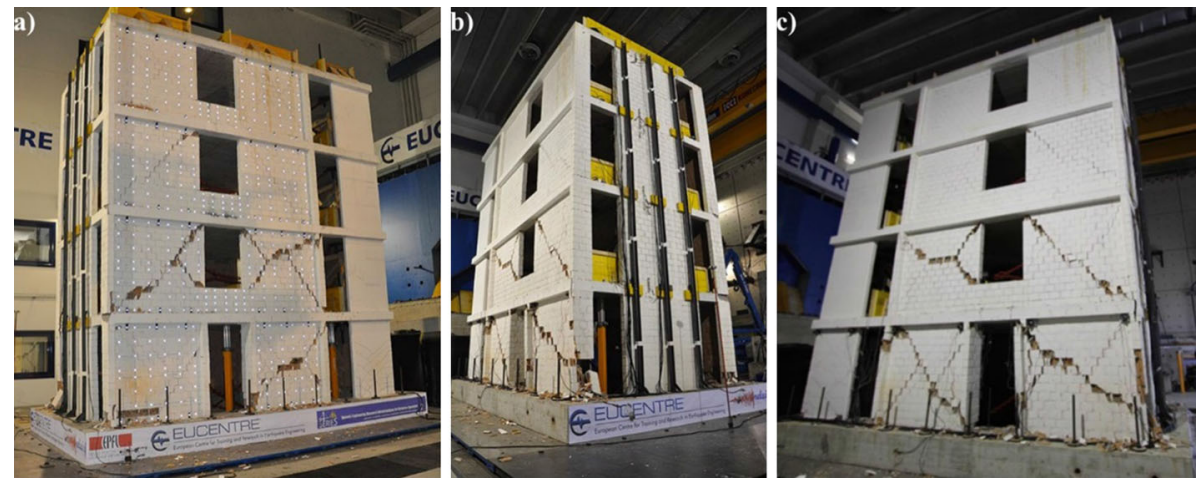

Fig. 8 Test 9 (0.9 g): Test unit after the final run
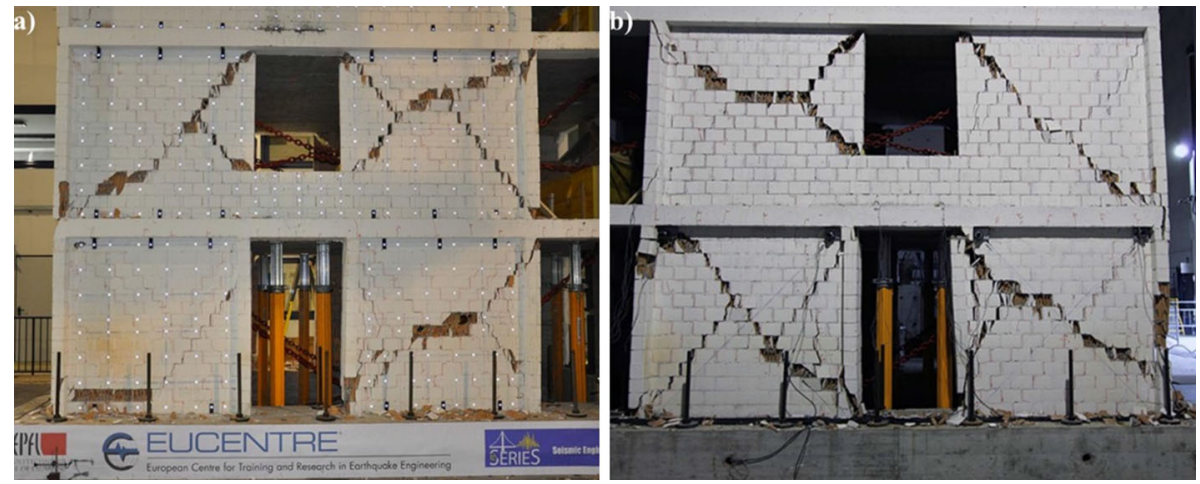

Fig. 9 Test 9 (0.9 g): In-plane loaded URM walls of west face (a) and east face (b)
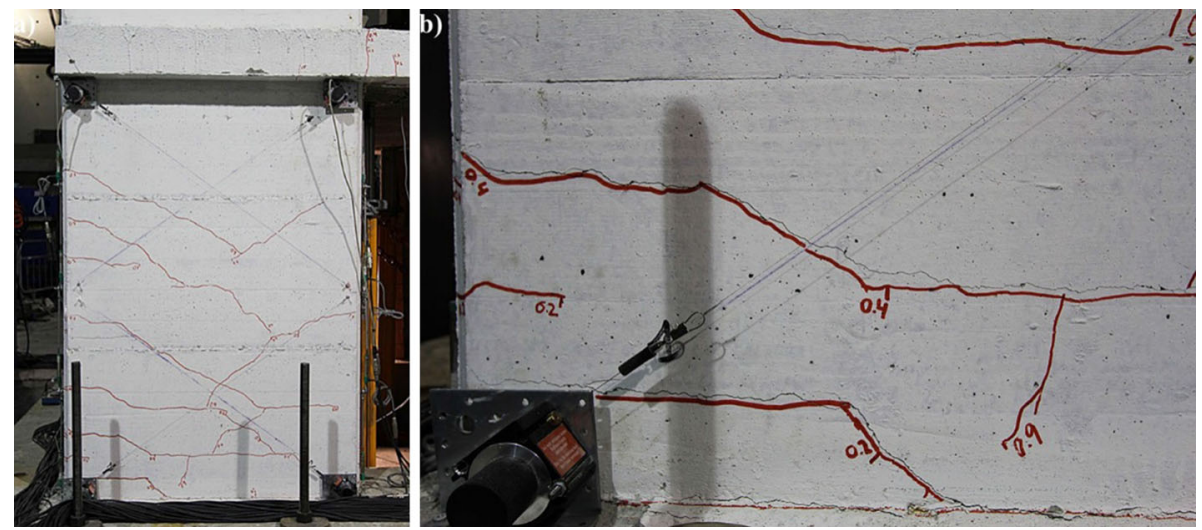

Fig. 10 PGA 0.9 g: Concrete wall: side view of first storey of the east RC wall (a) and zoom-in of south, bottom corner of this wall (b) 

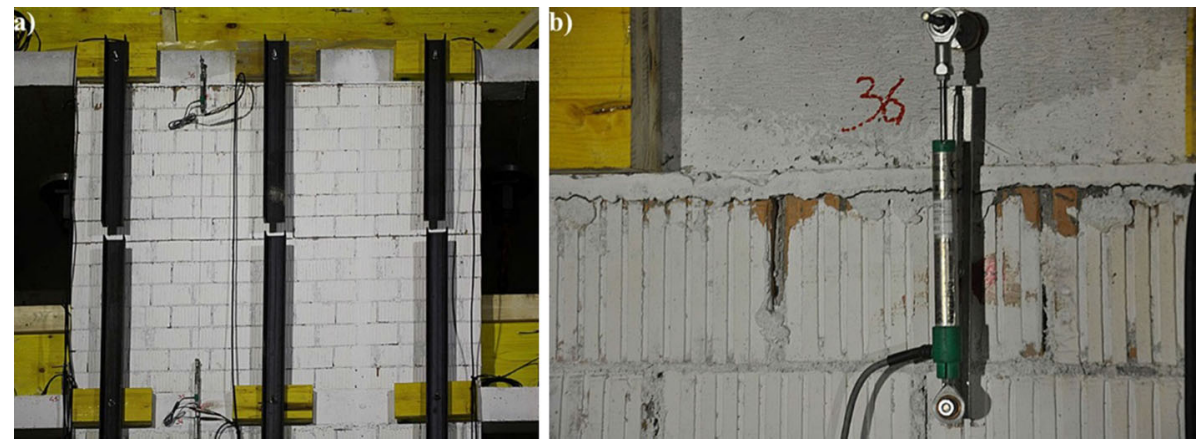

Fig. 11 PGA 0.9 g: out-of-plane failure in URM wall at the fourth storey of north face: horizontal crack at mid-height of N4 (a) and horizontal crack at top of N4 (b)

The final tests (Test 9) brought the structure rather close to collapse, since the four, inplane loaded URM walls of the first and second stories lost their horizontal and axial loadbearing capacity (Figs. 8,9). At the end of the test, the axial load was carried by the two RC walls, which had yielded but were far from failure (Fig. 10), and the URM walls that were loaded out-of-plane. To prevent collapse, steel props supporting the first storey slab were installed immediately after this test. It must be assumed that the structure would have partially collapsed at its north end, had it been subjected to bi-directional horizontal shaking. This is confirmed by a comparison of drift capacities obtained from quasi-static cyclic tests to the drift demands imposed during the last run, which showed that the walls had exceeded the drift capacities associated with axial load failure (Beyer et al. 2014).

The first significant out-of-plane movements of the out-of-plane loaded walls were only observed during the last run: the fourth-storey panel of the north face (N4) showed a classical out-of-plane rocking mechanism with the formation of hinges at the top, bottom and mid-height of the wall. During the test, the panel touched the inner timber support structure (see Appendices), which had been installed to prevent out-of-plane collapse of the URM walls that were loaded out-of-plane (see Fig. 11a). After the test, horizontal cracks over the entire wall length were observed at mid-height and at the top and bottom of the wall (Fig. 11). The walls on the south face did not show signs of significant out-of-plane movement or even failure. Note that the mass of the out-of-plane loaded URM walls was not represented correctly in the test: to replicate the out-of-plane response of these walls correctly, the additional mass should have been smeared over the height of the walls. This was not done, but the additional mass for all walls was included in the form of lumped masses at the storey heights. Hence, the out-of-plane behaviour of the URM walls in the test was less critical than it would have been in reality. This was, however, a conscious choice in the test design for two reasons: First, adding smeared masses to the out-of-plane loaded walls is rather difficult to achieve. Second, the authors wanted to avoid premature out-of-plane failure of the URM walls, which could have prevented testing the model up to in-plane failure.

\subsection{Failure mode}

This section describes the failure mode of the in-plane loaded walls of the east and west faces as observed after the last run (Test 9) and the out-of-plane response of the URM walls of the north and south faces. 
The uni-directional shake-table loaded the structure along its longitudinal axis in a north-south direction. Since the structure was not symmetrical about its east-west axis, the behaviour of the structure was different for loading in the positive and negative direction (for the sign convention see Fig. 3). When the structure was loaded in the negative direction, the axial force in the URM walls at the north end increased, while it decreased in the RC walls. Due to the reduced axial force, the RC wall developed shear-flexure cracks over the entire height of the first storey. The maximum residual width of these cracks was approximately $1 \mathrm{~mm}$, indicating that the longitudinal reinforcement had yielded (Fig. 10). The axial force in the central URM walls remained approximately constant, though small variations might have been caused by the different types of horizontal elements framing from the left and right into these URM walls (RC slab only vs. RC slab plus masonry spandrel). Since the deformation capacity of URM walls decreases with increasing axial load (Lang 2002; Petry and Beyer 2014b), the outer URM walls failed for loading in the negative direction, which is indicated by the compression failure at the toe of wall WN1 and the shear crack reaching from the outer bottom corner to the inner top corner of wall EN1 (Fig. 9). The different failure modes of these two walls show that, although the structure was symmetric along its NS-axis, the behaviour of the east and west faces was not exactly identical. The difference was most likely due to slight variations in the material properties. Significant accidental rotations of the structure about its vertical axis were excluded based on the recording of accelerometers on all four slabs.

When the structure was loaded in the positive direction (towards the south), the axial force in the outer URM walls decreased and thus led to a rocking motion of these walls (see the video on http://eesd.epfl.ch/; videos of the tests are also included in the database presented in the Appendices). The central walls were subjected to similar demands for the two loading directions and therefore developed the typical x-type crack pattern, which is well known from quasi-static cyclic tests with symmetric cycles. For loading towards the south, the axial force in the RC wall increased and-according to numerical investigations (Sect. 5) - the two RC walls carried, at this point, approximately two thirds of the total base shear. Since the wall was in compression, the residual crack widths remained close to zero, in fact indicating that for this loading direction the RC wall had not yet yielded.

One further particularity of the damage pattern (Figs. 8, 9) is the significant damage to the URM walls of the second storey. In fact, the second-storey walls reached similar limit states as the first-storey walls. In URM buildings with no RC walls, the walls of the first storey are typically subjected to the largest damage, while walls of the stories above are often only subjected to minor damage (e.g., Benedetti et al. 1998). This damage distribution results from the global behaviour of URM buildings as "shear beam", which leads to the largest inter-storey drifts at the first storey (e.g. Tomaževič 1999). In a structure with URM and RC walls like the one tested here, the URM walls, which behaviour is dominated by shear deformations, are coupled to slender RC walls, which deform chiefly in a flexural mode. As a result, the displacement profile is almost linear over the height of the building, and the damage therefore spreads over several stories. This aspect of the behaviour is further discussed in Sect. 4, where the drift and acceleration profiles are presented.

During the last run, the second, third and fourth-storey walls on the north side showed large out-of-plane displacements due to rocking of the walls. The first-storey wall on the north side and all walls of the south side did not show significant out-of-plane displacements. The difference in response of south- and northwalls relates to the different boundary conditions. The north-walls are flanked by URM walls. When the wall is pushed towards the south, the axial force in these walls decreases, and the top slab even uplifts when the flanking walls rock. As a result, the north walls are at some instances during the shaking 
subjected to zero axial load and without vertical restraint. It is during these instances that the largest out-of-plane displacements of the north-walls are observed. The south walls, on the contrary are flanked by RC walls, which do not permit the slab to uplift, and as a result, much smaller, out-of-plane displacements than on the north side develop. A more in-depth discussion of the out-of-plane behaviour and results of numerical investigations on the effect of these boundary conditions are reported in Tondelli and Beyer (2014).

\section{Quantitative results}

A large set of instruments was used to monitor the response of the test unit (see Sect. 2.3 and Appendix 3 to this paper). This section presents results that characterise the in-plane response of the test unit, i.e., the force-displacement response and the acceleration and drift profiles. The results are particularly discussed with regard to the influence of increasing nonlinearity on the response quantities and with regard to the difference in response for the positive and negative loading direction.

\subsection{Force-displacement response}

Unlike in quasi-static cyclic tests, in which the applied forces can be measured directly through load cells or pressure gauges, the base shear in shake-table tests needs to be derived from several measured quantities. Using the instrumentation described in Sect. 2.3, the base shear can be obtained in three different ways:

- $V_{b, A C T}$ : Force of the actuator of the shake-table minus the inertia force of the table and foundation. The latter can be computed from the accelerometer mounted on the table and the mass of the foundation and table. The masses are summarised in Table 12.

$$
V_{b, A C T}=F_{A C T}-\left[\text { Acc }_{1} \cdot\left(M_{\text {Found }}+M_{\text {ShakeTable }}\right)\right]
$$

- $V_{b, A C C}$ : Sum of the inertia forces of the four stories, where the inertia forces are computed from the accelerometers placed on each floor and from the storey mass.

$$
V_{b, A C C}=I_{1, A C C}+I_{2, A C C}+I_{3, A C C}+I_{4, A C C}
$$

- $V_{b, M A R K}$ : As $V_{b, A C C}$, but the floor accelerations are derived from the optical measurements of the markers on the foundation and slabs.

$$
V_{b, M A R K}=I_{1, M A R K}+I_{2, M A R K}+I_{3, M A R K}+I_{4, M A R K}
$$

All three methods suffer from certain shortcomings:

- $V_{b, A C T}$ : Next to the inertia force of the table and foundation, the actuator force also comprises the friction force between the table and rails and any friction force in the actuator or the hydraulic system. This is particularly evident for the runs with small PGAs.

- Both $V_{b, A C C}$ and $V_{b, M A R K}$ assume that the system can be approximated as a lumpedmass system. This approximation seems, however, reasonable because the largest part of the mass is concentrated in the slabs and the additional masses placed on the slabs. Moreover, out-of-plane deformations of the north and south URM walls are small (with the exception of Wall N4 during Test 9). 
- $V_{b, A C C}$ : The accelerometers of the third and fourth floors were saturated during Tests 8 and 9, and therefore, the base shear can only be computed from accelerometer measurements up to Test 7.

- $V_{b, M A R K}$ : Computing accelerations from the optical measurements, which were recorded with ten cameras, requires two steps: First, the measurements from the individual cameras need to be synchronised. Second, the displacement histories need to be differentiated twice in order to obtain accelerations. The differentiation introduces significant noise in the signals, which is reduced by filtering the signal with a secondorder Butterworth Lowpass Filter with a cut-off frequency of $12 \mathrm{~Hz}$ (Appendix 4). Both steps introduce errors into the base shear estimation. In addition, when compared to the accelerometer readings, the measurement frequency is considerably lower $(60 \mathrm{~Hz}$ instead of $1024 \mathrm{~Hz})$.

To obtain the hysteretic behaviour of the structure, the force is plotted against the average drift of the building, which is evaluated as the top displacement relative to the foundation divided by the height of the structure. The pushover curves for the two loading directions are constructed by plotting for each run the peak base shear and peak drift in the negative and positive loading direction. The peak drift is the maximum average drift over the height of the test unit that was recorded in the negative and positive loading direction, respectively (Fig. 12). The peak base shear values in the positive and negative loading direction are the maximum shear-force values in the negative and positive loading direction, respectively. Considering the advantages and disadvantages of the different methods for computing the base shear, the base shear of the pushover curve was obtained as follows: the base shear computed from accelerometer measurements seems most reliable but is not available for Tests 8 and 9. Since the base shear computed from the marker measurements agrees well with the base shear computed from the accelerometer measurements for Tests 1-7, one can assume that for Tests 8 and 9, the base shear derived from the marker displacements leads to reliable estimates of the actual base shear. The base shear values of the final pushover curve in Fig. 13 are therefore derived from accelerometer measurements for Tests 1-7 $\left(V_{b, A C C}\right)$ and from marker measurements for Tests 8 and $9\left(V_{b, M A R K}\right)$.
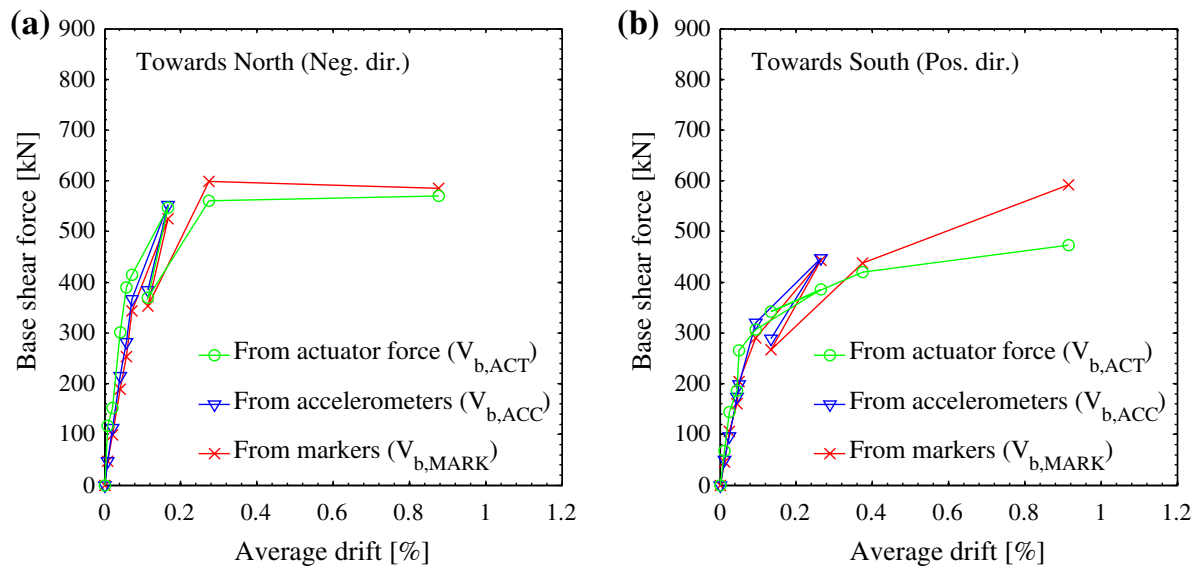

Fig. 12 Pushover curves for the negative (a) and positive (b) loading direction 

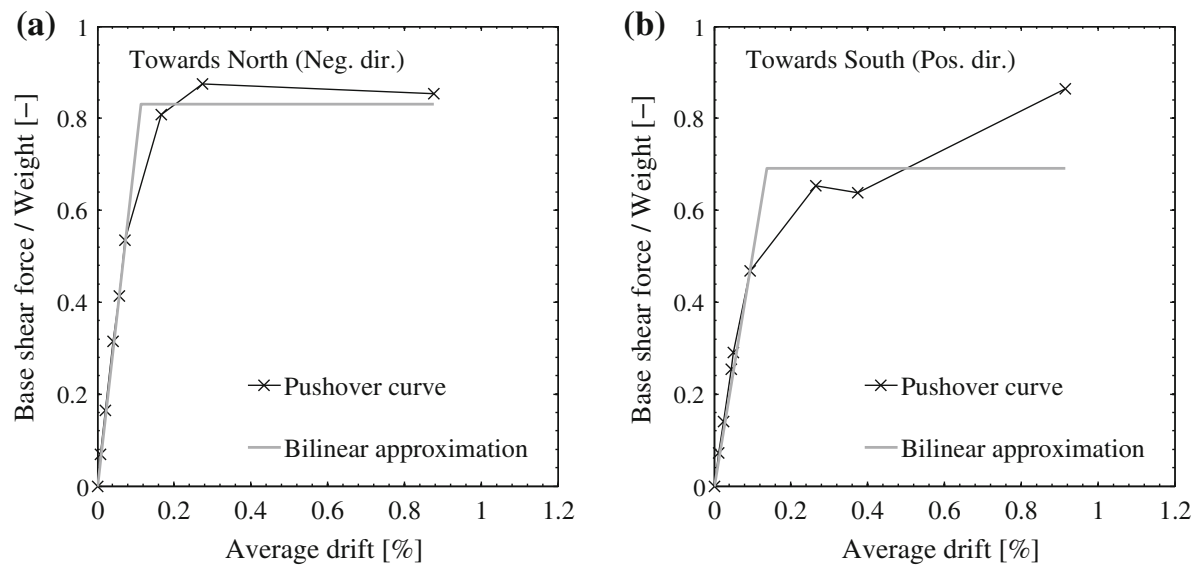

Fig. 13 Bilinear approximation of the pushover curves for the negative (a) and positive (b) loading direction

Comparing the pushover curves for the negative and positive loading direction shows that the stiffness of the structure in the elastic range is - as expected-rather similar for the two loading directions. The base shear capacity of the structure is, however, significantly larger for the negative loading direction than for the positive loading direction. For the negative loading direction, the axial force and therefore also the shear-force capacity of the outer URM walls increase and decrease for the positive loading direction. The moment capacity of the RC walls is not as sensitive to the change in axial force as the shear-force capacity of the URM walls. As a result, the base shear capacity of the structure is larger for loading in the negative than for loading in the positive direction. The curves further show that the test unit reached its maximum force capacity during Test 8 for the negative direction of loading. This agrees with the observation in Sect. 3.1 that Test 8 led to the onset of damage concentration in a single, diagonal crack; from tests on single URM walls, such damage concentration is known to indicate that the peak strength has been reached or passed (Sect. 3.1, Petry and Beyer 2014b).

The bilinear force-displacement curves were constructed as follows: (1) The initial stiffness was defined as the secant stiffness at $50 \% V_{\text {peak }}$; (2) the strength characterising the plastic branch of the approximation was computed in such a way that the area underneath the bilinear curve was equal to the area underneath the experimental forcedisplacement response. The yield drifts are similar for the two loading directions $\left(\delta_{y}^{+}=0.11 \%, \delta_{\mathrm{y}}^{-}=-0.14 \%\right)$. During Test 9 , when the structure failed, the structure reached displacement ductilities of $\mu_{\Delta}^{+}=7.7$ and $\mu_{\Delta}^{-}=6.7$ in the positive and negative direction. In the previous run (Test 8), the test unit underwent displacement demands that corresponded to displacement ductilities of $\mu_{\Delta}^{+}=2.4$ and $\mu_{\Delta}^{-}=2.7$, which can be taken as estimates of the displacement capacities at the limit state "Significant Damage".

The base shear-drift hystereses for the nine runs are shown in Fig. 14. For Tests 1-7, the base shear was computed from the accelerometer measurements $\left(V_{b, A C C}\right)$; for Tests 8 and 9 , it was computed from the marker measurements $\left(V_{b, M A R K}\right)$. For the latter, the resulting hysteresis curves are less smooth due to the smaller recording frequency and poorer precision, since the accelerations were derived from displacement measurements. The grey, vertical lines indicate the yield drifts as found from a bilinear approximation of the 

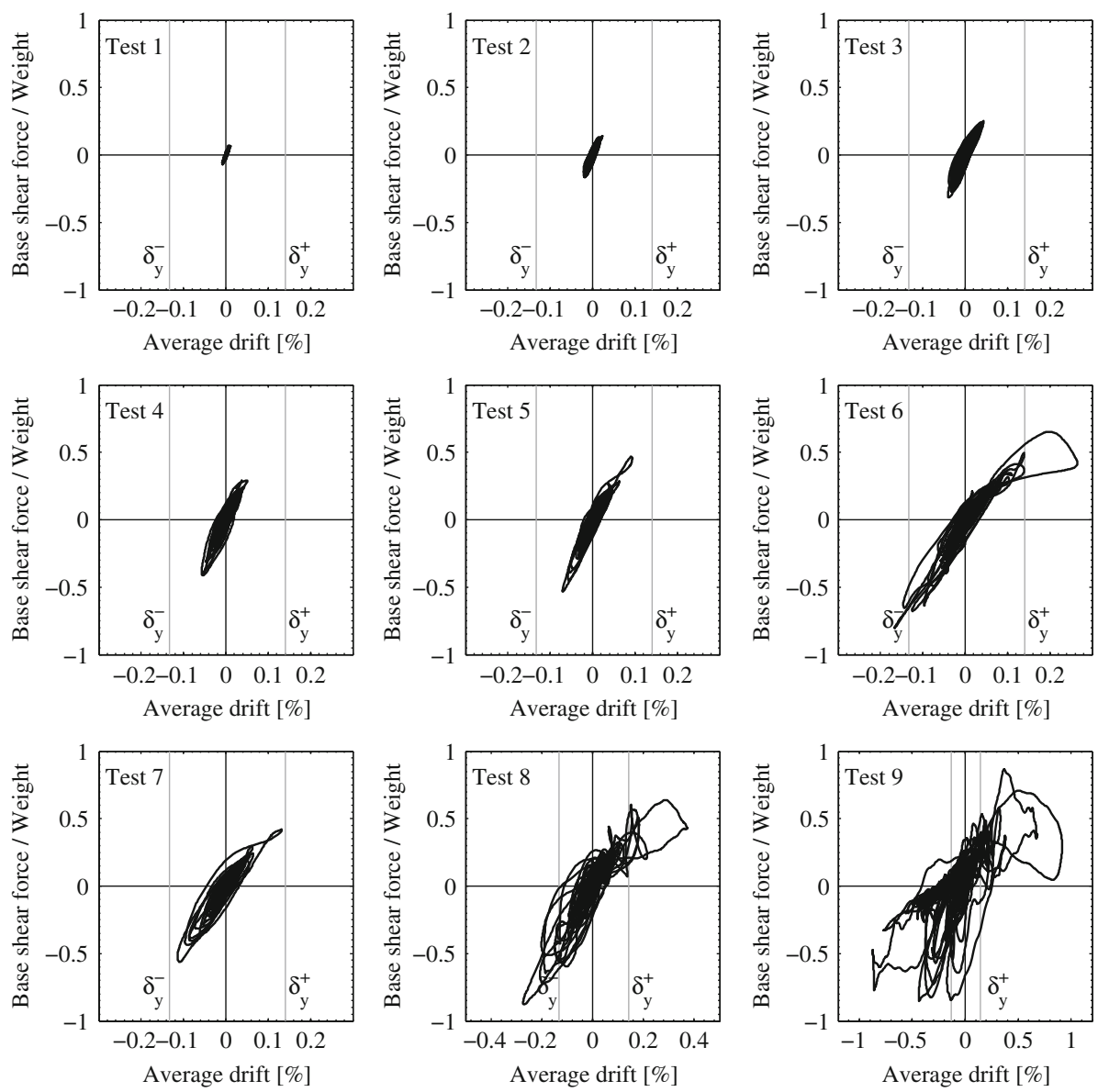

Fig. 14 Force-displacement hystereses for the nine runs. Note that the scale of the $x$-axis for Tests 8 and 9 differs from the scale used for Tests $1-7$

pushover curves that were constructed using $V_{b, A C C}$ for Tests 1-7 and $V_{b, M A R K}$ for Tests 8 and 9 (Fig. 13).

\subsection{Acceleration profiles and storey response spectra}

The asymmetry in the response due to the asymmetric building layout is also reflected in the acceleration envelopes. For small accelerations, the acceleration profiles have similar shapes for the positive and negative direction. For larger accelerations, the acceleration profile is rather constant over the height for the negative direction but increases from the foundation to the top for loading in the positive direction. As examples, the acceleration envelopes for the first and last run are shown Fig. 15. The plots of this figure show the positive and negative envelopes as derived from the accelerometer and marker signals (see previous section). The comparison of the two sets of curves shows that the marker signals yield reasonable approximations of the peak accelerations and can complement the results from the conventional instrumentation when the accelerometers are saturated, as seen in 

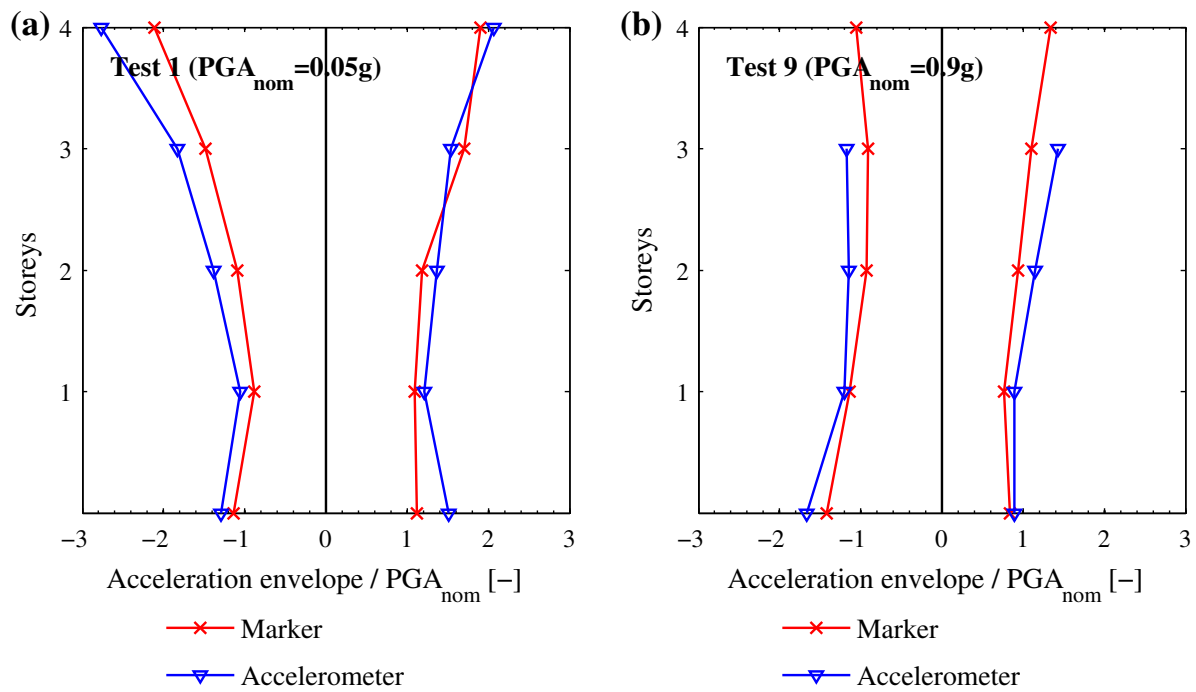

Fig. 15 Acceleration envelopes for the first test (a) and last test (b)
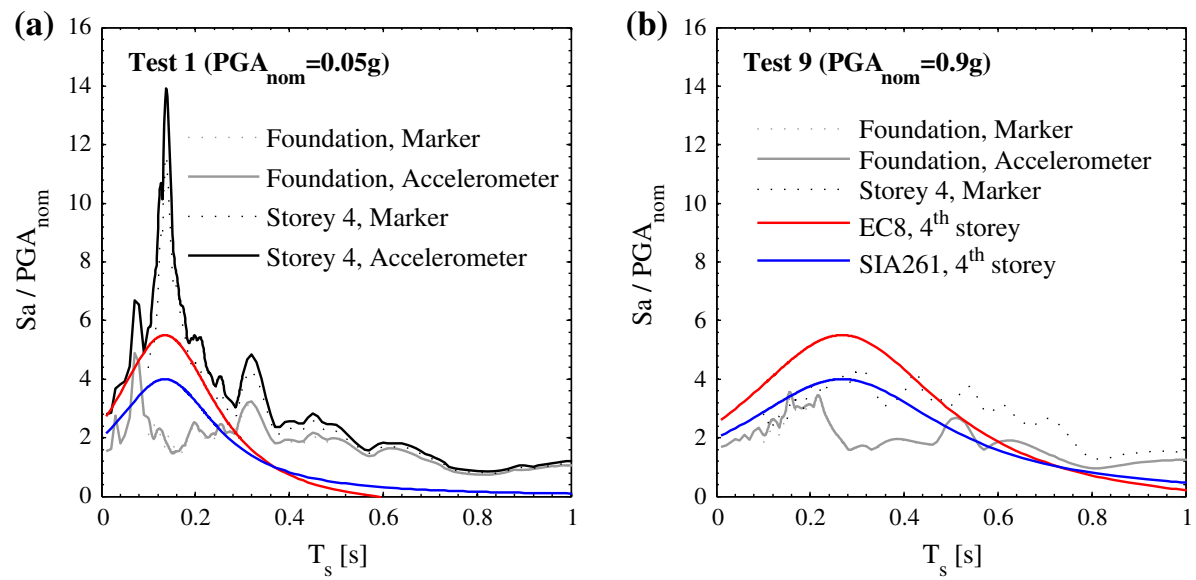

Fig. 16 Storey response spectra: Comparison of storey response spectra in codes to the storey response spectra computed from the accelerations that were recorded for the fourth storey during the first (a) and last (b) test. For comparison, the response spectra for the recorded foundation acceleration is also shown

Tests 8 and 9. However, due to the filter frequency of $12 \mathrm{~Hz}$, the acceleration derived from the marker recordings is meaningless in the short-period range.

Figure 16 shows storey response spectra of the top storey for the first and last run. The storey response spectra computed from the recorded signals are compared to the storey response spectra in two codes (i.e., Eurocode 8 [CEN 2004b] and the Swiss standard SIA 261 [2003]), which are provided for the design of non-structural elements. In Eurocode 8, the spectral acceleration of a non-structural element with a fundamental period $T_{a}$ and placed at level $Z$ above the foundation within the structure is given as: 

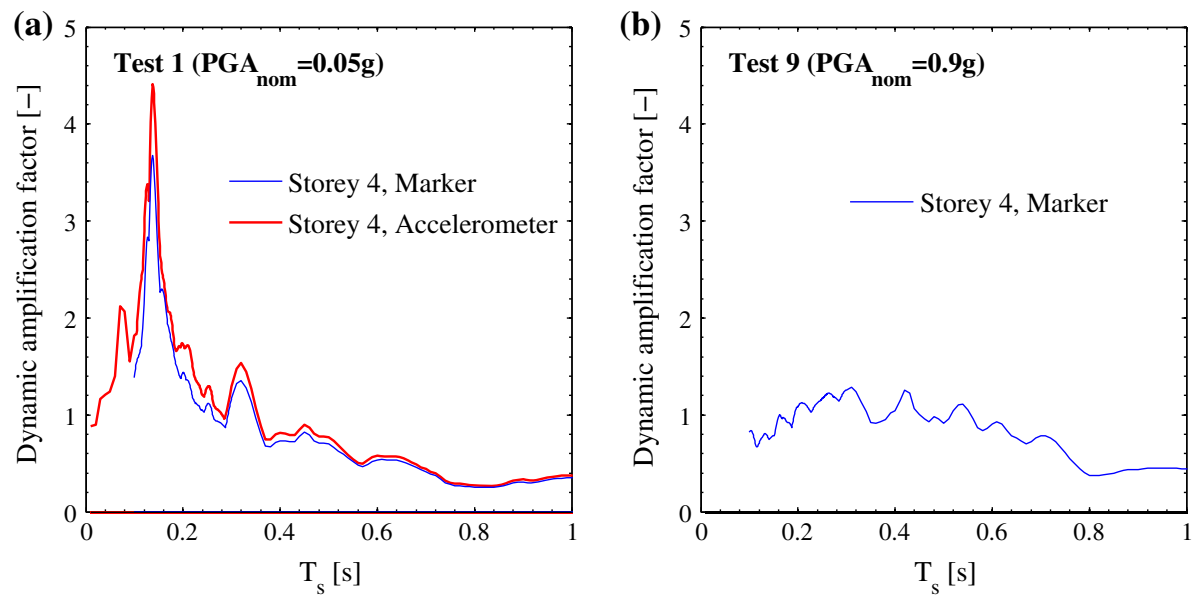

Fig. 17 Dynamic amplification spectra for the fourth storey during the first (a) and last (b) test

$$
S_{a}=\alpha S\left[\frac{3(1+Z / H)}{1+\left(1-T_{a} / T_{1}\right)^{2}}-0.5\right]
$$

where $S_{a}$ is the acceleration at level $Z ; \alpha$ is the peak ground acceleration expressed in $g$ (assumed equal to the peak table acceleration); $S$ is the coefficient accounting for the site class (set to 1 ); $H$ is the total height of the structure; $T_{1}$ is the vibration period of the first mode of the structure. In the Swiss standard SIA 261, the corresponding equation is:

$$
S_{a}=2 \gamma_{f} \frac{a_{g}}{g} S \frac{1}{q_{a}}\left[\frac{(1+Z / H)}{1+\left(1-T_{a} / T_{1}\right)^{2}}\right]
$$

where $\gamma_{f}$ is the importance factor (assumed equal to 1 ); $a_{g} S / g$ is equivalent to $\alpha S$ in the equation of Eurocode 8; $q_{a}$ is the q-factor of the non-structural element (assumed equal to 1). The spectrum in SIA 261 is based on the Eurocode 8 equation but does not lead to negative spectral accelerations for large $T_{a} / T_{1}$ ratios as with the Eurocode 8 equation. It also introduces a behaviour factor $q_{a}$ for the non-structural element.

Both equations underestimate the amplification of the spectral accelerations around the fundamental period of the structure when the structure is largely elastic (Fig. 16a) but estimate it rather well when the structure responds highly inelastically (Fig. 16b). The attained displacement ductility during Test 9 was approximately seven for both loading directions.

As the structure was increasingly damaged, the fundamental period of the structure lengthened. The fundamental period was determined as the period with the largest dynamic amplification, which is defined as the ratio between the spectra at the different stories and the spectrum at the foundation level (Fig. 17). Table 2 summarises the fundamental periods obtained from the accelerometer $\left(T_{1 a}\right)$ and marker signals $\left(T_{1 b}\right)$; the correspondence of the two period estimates is very good. Also included in Table 2 are the fundamental periods that were obtained from the structural identification after the tests $\left(T_{1 c}\right)$, which are generally shorter than the actual period during the shaking $\left(T_{1 a, b}\right)$. For the runs which remained largely in the elastic domain (Test $1-5$ ), the ratio $T_{1 a} / T_{1 c}$ is on average around one; for the runs in the inelastic domain, the ratio increases to approximately 1.2. 
Table 2 Evolution of fundamental periods in the longitudinal direction of the building

\begin{tabular}{llllll}
\hline $\begin{array}{l}\text { Test } \\
\text { number }\end{array}$ & $\begin{array}{l}\text { Nominal } \\
\text { PGA (g) }\end{array}$ & $\begin{array}{l}T_{1 a} \text { from dynamic } \\
\text { amplification } \\
\text { (3rd storey) } \\
\text { Accelerometers }(\mathrm{s})\end{array}$ & $\begin{array}{l}T_{1 b} \text { from dynamic } \\
\text { amplification } \\
\text { (4th storey) } \\
\text { Markers (s) }\end{array}$ & $\begin{array}{l}T_{1 c} \text { from structural } \\
\text { identification } \\
\text { after the run }\end{array}$ & $\begin{array}{l}\text { Ratio } \\
T_{1 a} / T_{1 c}\end{array}$ \\
\hline Pre-test & & & & 0.13 & 1.01 \\
1 & 0.05 & 0.13 & 0.13 & 0.13 & 1.06 \\
2 & 0.1 & 0.14 & 0.14 & 0.13 & 0.97 \\
3 & 0.2 & 0.15 & 0.14 & 0.15 & 0.91 \\
4 & 0.3 & 0.15 & 0.16 & 0.16 & 0.85 \\
5 & 0.4 & 0.14 & 0.14 & 0.17 & - \\
6 & 0.6 & 0.23 & 0.23 & - & 1.21 \\
7 & 0.4 & 0.22 & 0.22 & 0.19 & 1.22 \\
8 & 0.7 & 0.26 & 0.26 & 0.21 & \\
9 & 0.9 & 0.29 & 0.29 & & \\
\hline
\end{tabular}

(a)

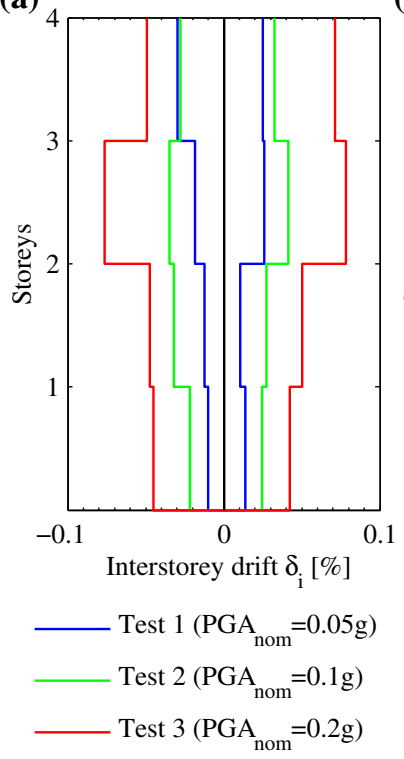

(b)

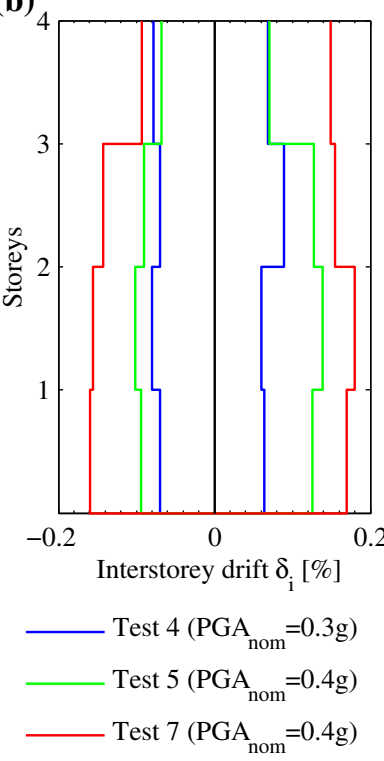

(c)
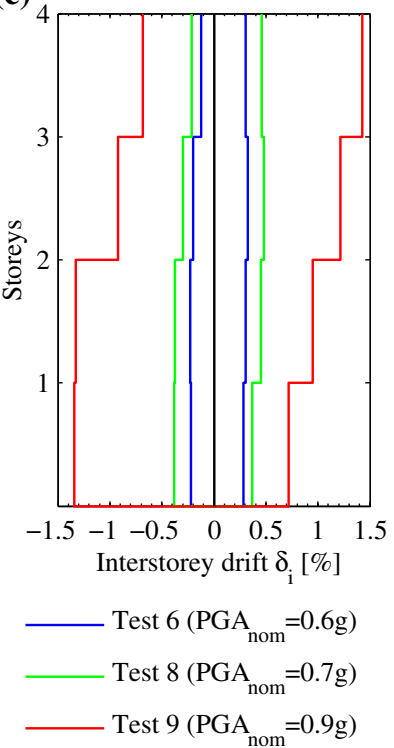

Fig. 18 Peak inter-storey drift envelopes

\subsection{Drift profiles}

The two particularities of the structure when compared to regular URM buildings without $\mathrm{RC}$ walls concerned the difference in behaviour for the two loading directions and the distribution of the damage over the two lower stories. Both points are also reflected in the drift profiles of the structure. 
Figure 18 shows the drift profiles for the nine runs. These drift profiles are envelopes of the positive and negative drift demands, which are in the following referred to as maximum and minimum peak drifts. Negative drifts are associated with a displacement in the negative direction (towards north) and positive drifts with a displacement in the positive direction (towards south); for the sign convention, see Fig. 3a. The drifts are inter-storey drifts and are computed from the horizontal displacements of the markers on the four slabs ( $i=0$ refers to the foundation):

$$
\delta_{i}=\frac{\Delta_{i}-\Delta_{i-1}}{h_{S t}}
$$

where $\Delta_{i}$ and $\Delta_{i-1}$ are the slab displacements and $h_{s t}$ is the clear storey height $\left(h_{s t}=1.4 \mathrm{~m}\right)$. The displacement of each slab is computed as an average horizontal displacement of six markers along the slabs.

The runs with $\mathrm{PGA}_{\text {nom }} \leq 0.4 \mathrm{~g}$ (Fig. 18a) yield drift profiles that are approximately equal for the two loading directions, indicating that for these levels of excitation, the structure responded largely in the elastic range and therefore symmetrically. For larger PGAs, the drift profiles in the positive and negative direction differ (Fig. 18b): for loading in the positive direction, the behaviour is dominated by the $\mathrm{RC}$ walls. The drift profiles therefore resemble the drift profiles of a cantilever wall under lateral loading with the largest drifts at the top of the wall. For loading in the negative direction, the URM walls control the behaviour, and the drift profile therefore resembles that of an inelastic shear beam-with the exception that the inelastic deformations are not just concentrated in the first storey but are distributed over the two bottom stories. Figure $18 \mathrm{c}$ shows also that the peak drifts approximately tripled from Tests 8 to 9 . Figure $19 \mathrm{a}, \mathrm{b}$ shows the peak drifts plotted against the spectral displacement and spectral acceleration at the fundamental period of the structure. The fundamental period is the period after the test ( $T_{1 a}$ in Table 2). Figure 19 includes the maximum storey drift values and the average drift over the height of the building. The peak values of both drift values scale approximately linearly with the spectral displacement, while the relationship with the spectral acceleration is non-linear.

(a)

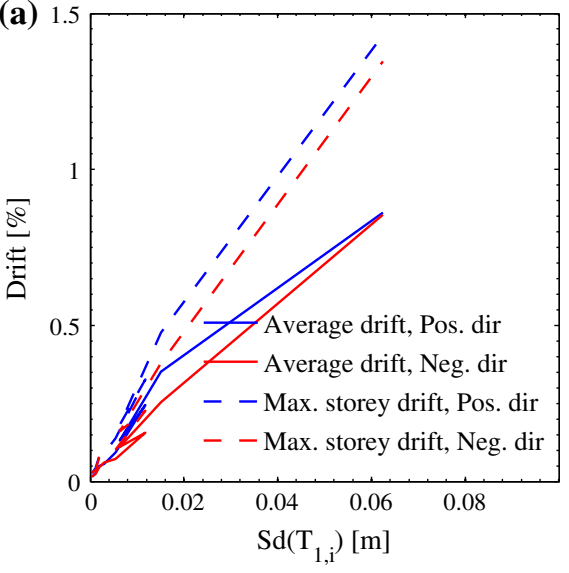

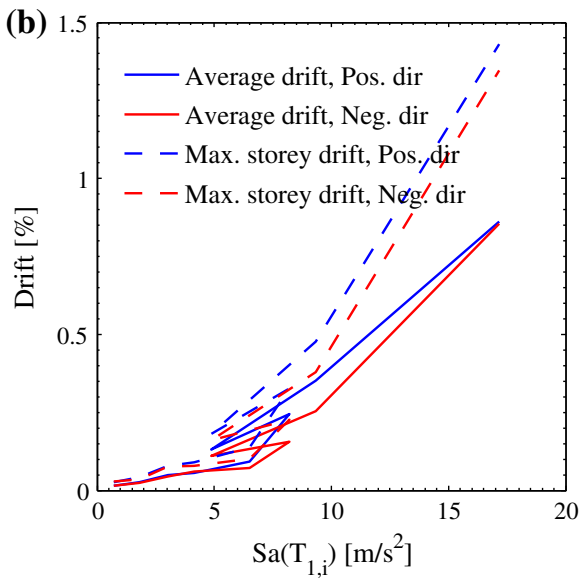

Fig. 19 Inter-storey drift as a function of the spectral values at the fundamental period in longitudinal direction determined before the run and for the recorded table acceleration 
(a)

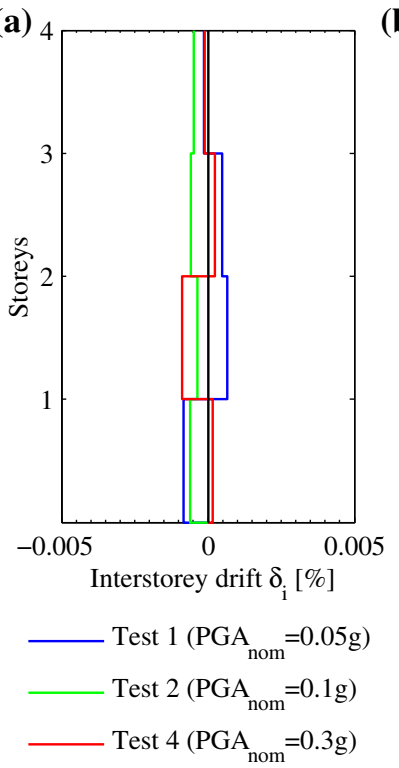

(b)

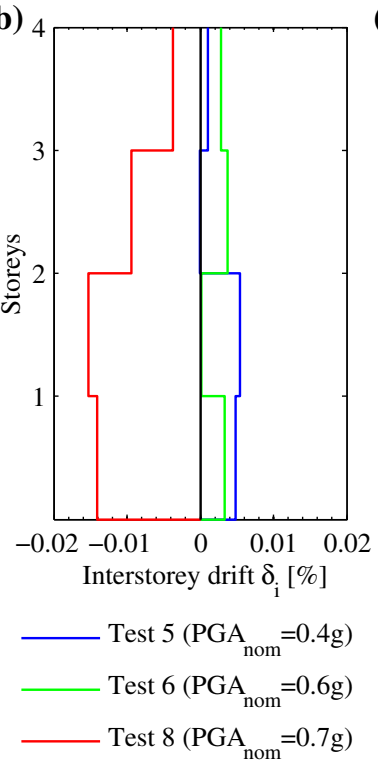

(c)

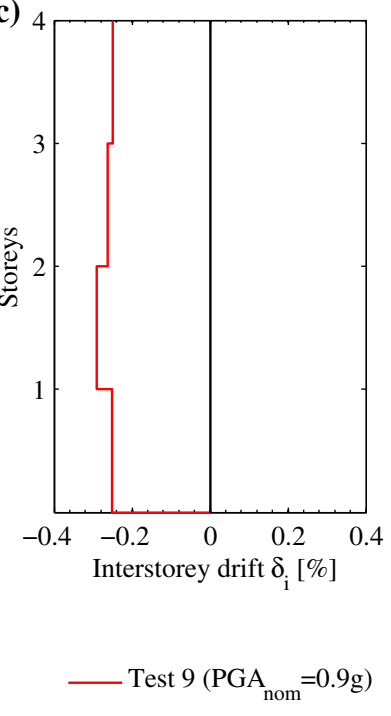

Fig. 20 Residual inter-storey drift profiles

Prior to Test 9, the damage was limited, which is also reflected in close-to-zero residual drifts (Fig. 20). At the end of the test, the maximum residual drift was $-0.29 \%$, confirming that the structure had failed when it was loaded in the negative direction. The residual inter-storey drift profile was computed as the average value of the last 500 points of the recording.

Damage to the masonry panel is better related to chord rotation than to the inter-storey drift as defined by Eq. (6). The chord rotation of a wall panel is defined as the inter-storey drift minus the rigid body rotation of the support of the panel, i.e., the rotation $\theta_{R B}$ of the slab or foundation on which the panel stands:

$$
\theta_{i}=\delta_{i}-\theta_{R B_{i-1}}
$$

For the first storey, the rigid body rotation is zero, since the foundation was quasi rigid and did not rotate. For the upper stories, however, the rigid body rotation is non-zero.

Figure 21 shows the drift profiles for Tests 8 and 9 at the two points in time when the maximum or minimum inter-storey drift was reached. For Test 8 , the rigid body rotation increases with height for the positive loading direction, which is in line with the observation that for this loading direction, the behaviour of the structure is controlled by the RC walls acting largely as elastic flexural beams. For the negative loading direction, the rigid body rotation is almost constant over the height and significantly smaller than for the positive loading direction, which shows that shear deformations dominated the behaviour. For Test 9, the contribution of the rigid body rotations to the inter-storey drift is less than seen in Test 8, which shows that the interstorey drifts are now largely related to damage to the URM walls rather than rotations of the slabs. 
(a)

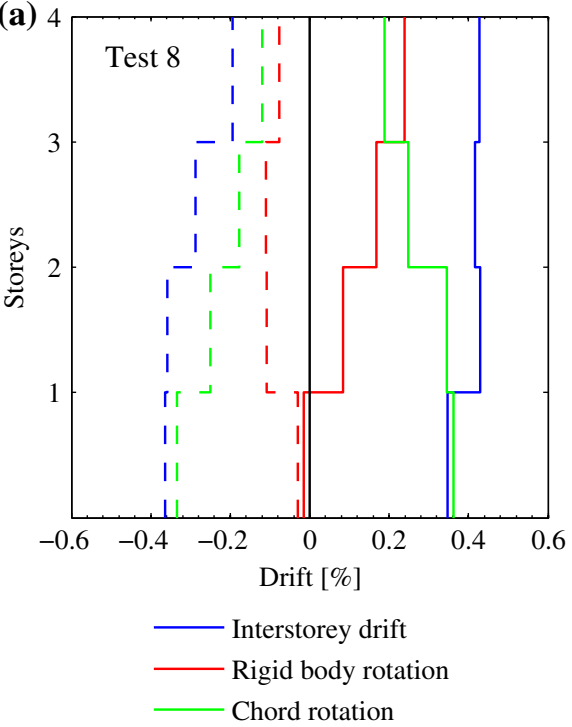

(b)

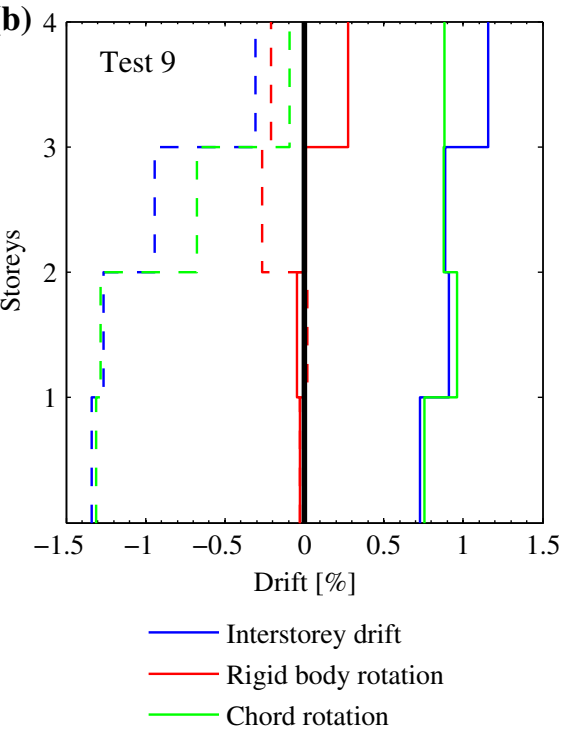

Fig. 21 Inter-storey drift, rigid body rotation and chord rotation for peak drift of Test 8 (a) and Test 9 (b). The dashed lines correspond to the negative loading direction (towards north) and the solid lines to the positive loading direction (towards south)

\section{Comparison of prediction to experimental results}

\subsection{Prediction of experimental results before the test}

To predict prior to the test the levels of shaking to which the test unit could be subjected, the performance of the test unit was assessed using the Capacity Spectrum Method. The objectives of the analyses were twofold: first, estimates of the peak accelerations were sought which induced limit states of significant damage to near collapse. Since no support structure was put in place, complete collapse of the test unit had to be avoided in order to protect the shake-table facility. Second, a somewhat conservative estimate of the expected maximum base shear force was needed to ensure that the capacity of the shake-table was not exceeded. For this purpose, simple pushover analyses investigating the sensitivity to the loading direction and the assumed effective width of the slab were carried out.

\subsubsection{Finite element model of test unit}

Since the test unit was symmetric about its north-south axis, a 2D model of one of the inplane loaded faces was analysed. The effect of the out-of-plane loaded walls on the inplane response was neglected. For the pushover analyses, a simplified micro model was built in which the bricks were represented by continuum elements and the joints by discontinuous interface elements (Lourenço 1996). The model was analysed using the finite element programme ATENA (Cervenka et al. 2010). For the sake of computational efficiency, the brick units were modelled at twice as large as in the test. Each brick was modelled as a separate unit, using plane stress isotropic elements of quadrilateral shape with elastic behaviour. Failure of the bricks was hence not captured by this model. 
The mortar joints were represented by interface elements of zero thickness. The initial failure surface of these elements, which characterises the peak strength of the joint, follows a Mohr-Coulomb law with an ellipsoidal failure surface in the tension regime (Beyer and Mangalathu 2014). Once the interface reaches a point on the failure surface, it loses its cohesion $(c)$ and tensile strength $\left(f_{t}\right)$. The residual failure surface accounts only for friction $(\mu)$. The material properties of the masonry were obtained from a preparatory study on the similitude of full- and half-scale masonry (Petry and Beyer 2014a) and are summarised in Appendix 2. The simplified micro model of the masonry walls makes use of the E-modulus of the masonry $\left(E_{m}=4500 \mathrm{MPa}\right)$ and the properties of the mortar-brick interface $\left(\mu=0.70, c=0.23 \mathrm{MPa}, \mathrm{f}_{t}=c / 2 \mu=0.16 \mathrm{MPa}\right)$.

While the masonry material properties were available before the shake-table tests, tests on concrete and reinforcing steel were only performed after completion of the shake-table tests. For this reason, nominal properties were assumed for concrete and steel when predicting the performance of the test unit. The concrete of walls and slabs was modelled with shells to which the inelastic constitutive concrete material law SBETA was assigned (Cervenka and Papanikolaou 2008). The pre-stressed concrete foundation was modelled with very stiff elastic-shell elements. The longitudinal reinforcement in walls and slabs was modelled as discrete reinforcement and the shear reinforcement with smeared reinforcement. Both types of reinforcement were assigned bilinear stress-strain characteristics with $E_{s}=200 \mathrm{GPa}, f_{s y}=550 \mathrm{MPa}$ and $f_{s u}=650 \mathrm{MPa}$ at $\varepsilon_{s u}=5 \%$. For the wall reinforcement, the assumed values turned out to be rather similar to the actual strength values $(+4 \%)$ but overestimated the strength of the slab reinforcement by $+12 \%$ (see Appendix 2).

\subsubsection{Pushover analyses}

The pushover analyses were conducted by applying equal horizontal forces at the four stories. The axial forces were modelled by vertical forces at the storey levels. It was assumed that the entirety of the axial forces was carried by in-plane loaded walls. The sum of the vertical forces applied to the 2D model corresponded therefore to half the weight of the test unit (including additional masses, excluding the foundation). The horizontal and axial forces were distributed along the length of the walls.

An important unknown in the analysis relates to the assumed effective width $b_{\text {eff }}$ of the $\mathrm{RC}$ slabs, which were reinforced with nets (diameter $10 \mathrm{~mm}$ at $100 \mathrm{~mm}$ distance) at the top and bottom of the slab. Priestley et al. (2007) recommend $b_{\text {eff }}=2 t_{w}$ for outer walls and $b_{\text {eff }}=3 t_{w}$ for inner walls, where $t_{w}$ is the width of the wall. Due to their flanges, the URM walls were positioned at a distance of $0.10 \mathrm{~m}$ to the slab edge (see Appendix 3). For this reason, the lower estimate of the effective slab width was assumed as $b_{\text {eff }}=3 t_{w}=0.30 \mathrm{~m}$. To obtain conservative estimates of the maximum base shear force, a second analysis set with $b_{\text {eff }}=1.0 \mathrm{~m}$ was performed.

For both effective slab widths, the pushover analyses were conducted for the two loading directions, i.e., towards north (negative loading direction) when the outer URM walls were subjected to an increased compression force and towards south (positive loading direction) when the RC walls were subjected to an increased compression force.

Figure 22 shows the four force-displacement curves. The two crosses along each curve indicate when the first storey drift exceeds for the first time 0.4 and $0.53 \%$. According to Eurocode 8, Part 3 (CEN 2005), these two drift values correspond to the drift limits of URM walls failing in shear for the limit states "Significant Damage" (SD) and "Near Collapse" (NC). Figure 23 shows the amplified deformed shapes for the two loading 

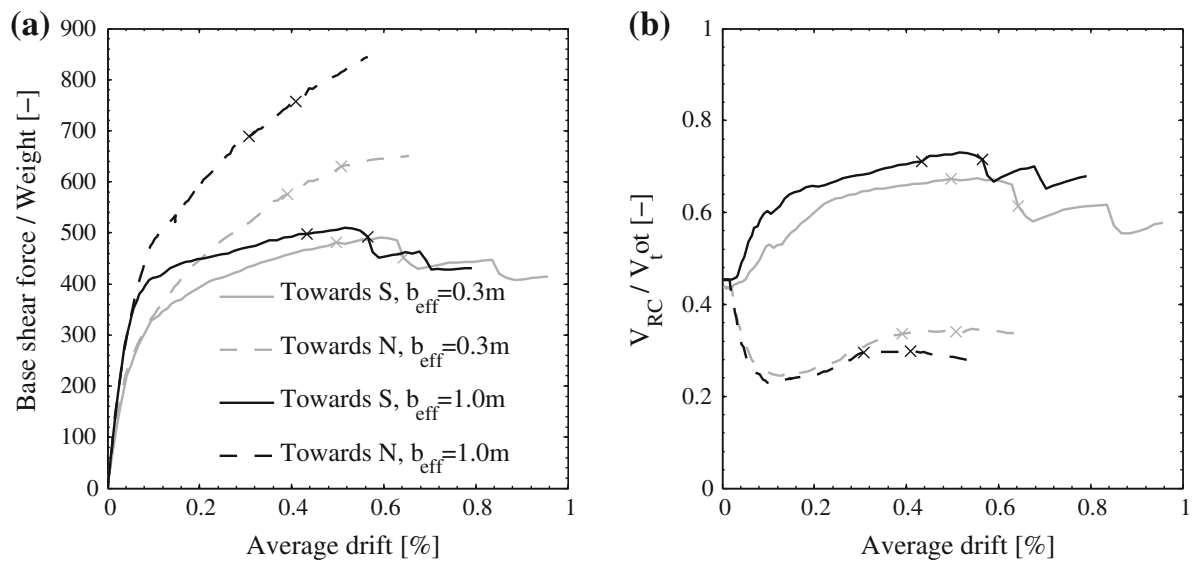

Fig. 22 Pushover curves from finite element analyses (a); contribution of RC walls to overall base shear capacity (b)

(a)

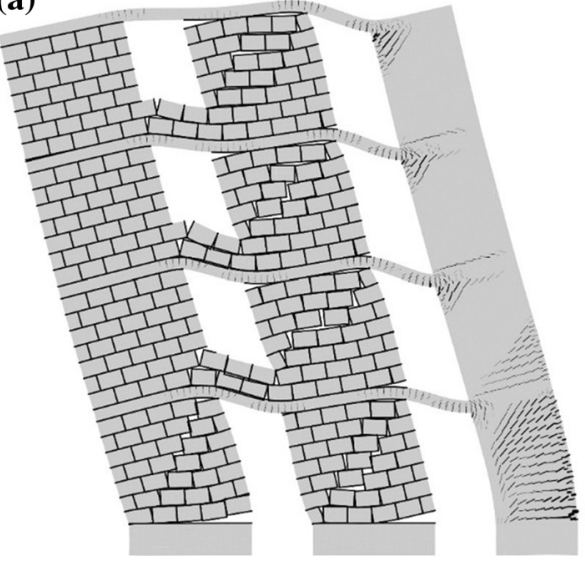

(b)

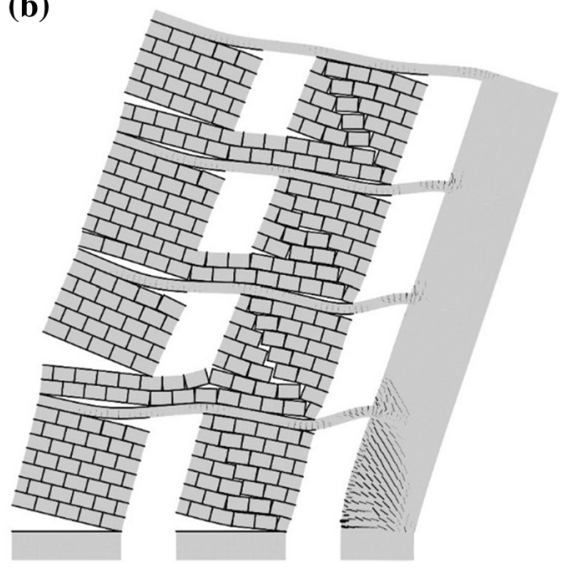

Fig. 23 Prediction: deformation pattern at $0.53 \%$ of first-storey drift for $b_{\text {eff }}=0.3 \mathrm{~m}$ : Towards north (a) and towards south (b)

directions and confirms that at least one of the URM walls of the first storey developed a behaviour that was controlled by shear deformations. The results for $b_{\text {eff }}=1.0 \mathrm{~m}$ showed that an exceedance of the base shear capacity of the Table $(1000 \mathrm{kN})$ was not to be feared, since the maximum base shear demand for a first-storey drift of $0.53 \%$ was only $757 \mathrm{kN}$ (Fig. 22a).

\subsubsection{Capacity spectrum method}

Knowing that the response of the shake-table never exactly corresponds to the input signal, the response spectrum of the input signal was approximated by a smooth spectrum when evaluating the expected performance of the test unit by means of the Capacity Spectrum 

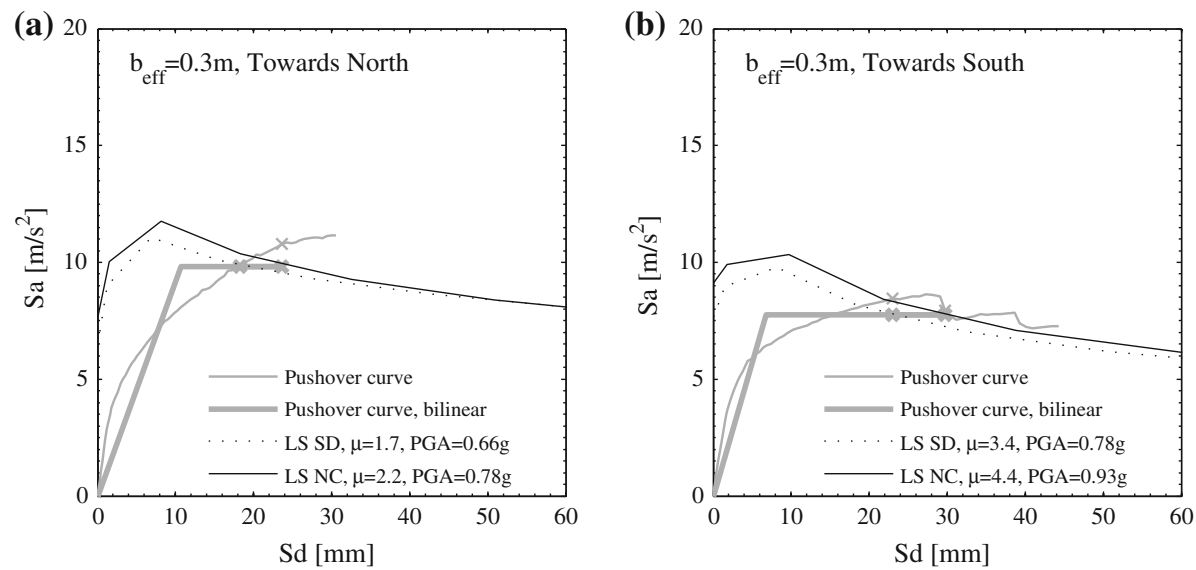

Fig. 24 Prediction: capacity spectrum method predicting the input PGA required to reach $\delta_{S D}=0.4 \%$ and $\delta_{N C}=0.53 \%$ first-storey drift, respectively

Method (Freeman et al. 1975). The smooth spectrum corresponds to the shape of the EC8Part 1 design spectrum for Soil Type D, but to improve the match with the spectral shape of the input signal, the plateau value was lowered from 2.5 to 2.1 times the PGA. The smooth spectrum is shown in Fig. 4, which shows also the response spectra of the input signal and the response spectra for the actual recorded table motions during testing. All spectra have been normalised by the nominal PGA, i.e., the peak acceleration of the intended input signal (Table 1, column 2). The comparison shows that in particular, around the first fundamental period $\left(T_{1}=0.13-0.29 \mathrm{~s}\right.$, Table 2$)$, the discrepancy between the input signal and the table response was, for some runs, significant.

The performance of the test unit was evaluated using inelastic response spectra (Fajfar 1999). For the assessment, the force-displacement curves for $b_{\text {eff }}=0.3 \mathrm{~m}$ were approximated by elasto-plastic curves which were constructed according to the following (Fig. 24): (1) The initial stiffness was defined as the secant stiffness at $70 \% V_{\text {peak }}$, where $V_{\text {peak }}$ is the maximum force up to $0.4 \%$ of the first storey drift; (2) the strength characterising the plastic branch of the approximation was computed in such a way that the area under the bilinear curve was equal to the area under the force-displacement response obtained from the numerical analysis. The area was computed up to $0.4 \%$ of the first storey drift. For each loading direction, the peak ground accelerations which lead to the SD and NC limit states of the smooth spectrum were computed (Fig. 24). For loading towards the north (i.e., when the compression force in the outer URM wall increases), the PGAs associated with one of the limit states are smaller than for loading in the positive direction. Hence, it was expected that the test unit would fail first when loading in the negative direction. For the SD-limit state, with a maximum inter-storey drift of $0.40 \%$, the estimated PGA was $0.66 \mathrm{~g}$, and for the NC-limit state with a limited inter-storey drift of $0.53 \%$, the estimated PGA was $0.78 \mathrm{~g}$.

\subsection{Comparison of numerical prediction to experimental results}

Figure 25 shows the comparison between the pushover curves obtained from the finite element analyses and the pushover curves constructed from the peak response values of the shake-table tests (Fig. 13). The prediction with $b_{\text {eff }}=0.3 \mathrm{~m}$ matches the experimental 

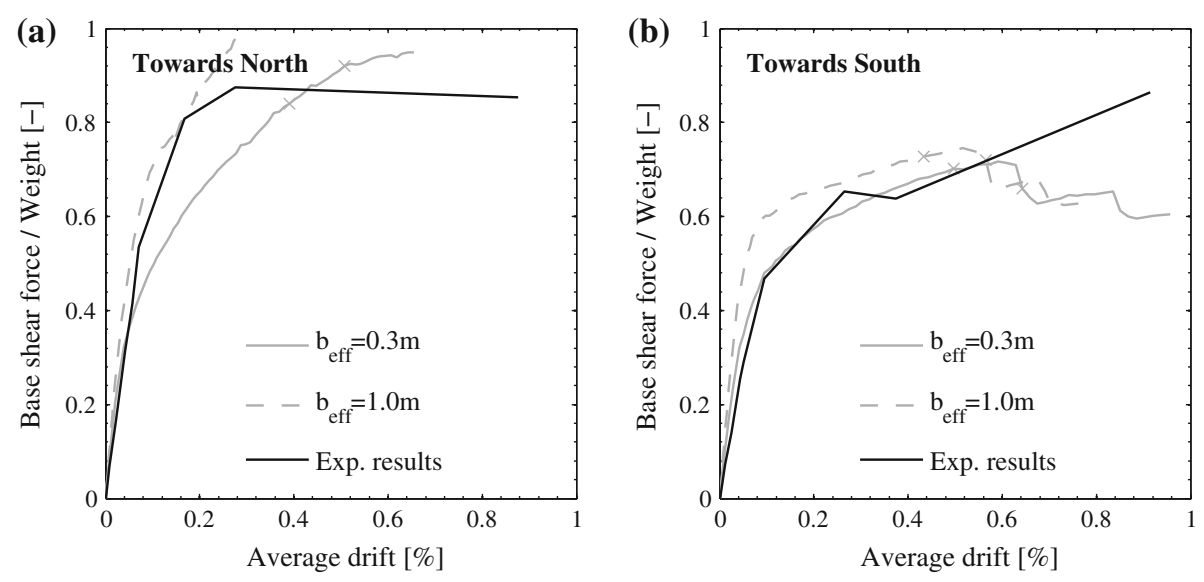

Fig. 25 Comparison prediction-experiment: pushover curves

results rather well for loading towards the south (Fig. 25b). Towards the north, the prediction with $b_{\text {eff }}=0.3 \mathrm{~m}$ matches the initial stiffness well but is then too soft. For the negative loading direction, not incorporating the damage to the bricks in the model leads to a significant overestimation of the base shear in the inelastic phase.

According to the results of the Capacity Spectrum Method, failure was expected for loading towards the north (negative loading direction). This agrees with the failure mechanism observed after Test 9 , which is characterised by shear failure of the URM walls of the first and second stories for loading in the negative direction. The SD limit state was just reached during Test 8 with a nominal PGA of $0.7 \mathrm{~g}$, which resulted in a maximum first-storey drift of $0.36 \%$ towards the north. The good agreement of prediction and observation shows that the Capacity Spectrum Method in conjunction with the 2D pushover analysis was able to capture the behaviour of the test unit rather well. The NC limit state was exceeded in Test 9 when the in-plane loaded URM walls lost their horizontal and vertical load-bearing capacity and the maximum inter-storey drift was $1.34 \%$. For this run, the PGA of $0.9 \mathrm{~g}$ exceeded the predicted PGA of $0.78 \mathrm{~g}$, which was expected to lead to the NC drift limit of $0.53 \%$.

According to the prediction, the limit state SD should have been reached during Test 8 $\left(\mathrm{PTA}_{\text {nom }}=0.7 \mathrm{~g}\right)$. However, if the response spectrum of Test 8 is compared to the response spectrum of the input signal and the smooth spectrum, one notices that the spectral value of the actual response spectrum of Test 8 at fundamental period $T_{1}=0.26 \mathrm{~s}$ is only about $60 \%$ of the spectral value of the smooth spectrum. For Test 9 , the spectral acceleration at the fundamental period is $75 \%$ of the smooth spectrum. Hence, considering the different nominal PGAs, from Test 8 to Test 9 the spectral acceleration at the fundamental period increased by approximately $60 \%$. This explains why the SD limit state was not reached during Test 8 but was largely exceeded during Test 9.

\section{Conclusions}

Strengthening unreinforced masonry (URM) buildings by adding reinforced concrete (RC) walls can be an attractive solution for the mitigation of seismic risks. At present, the design of such structures is, however, often oversimplified by assigning all horizontal forces to the 
RC walls and neglecting the contribution of the URM walls. Such a design approach has several implications, as follows: (1) neglecting the contribution of the URM walls is conservative from a strength point of view. (2) Even if the contribution of the URM walls is neglected, it is important that the structure be designed for drift limits appropriate for URM walls, as the URM walls have to continue transferring gravity loads. (3) The experimental results have shown that the response of the mixed structure differs significantly from the response of a structure with either RC or URM walls. Such a simplified design, therefore, does not capture the real behaviour of the structure.

The uni-directional, shake-table test of the four-storey structure with RC and URM walls that was presented in this paper highlighted the impact of adding $\mathrm{RC}$ walls to an URM building. Unlike for URM buildings where the damage to the walls concentrates typically in the bottom storey, adding RC walls leads to a better distribution of the damage over the height of the building. In the four-storey test building, the two lower stories were subjected to similar inter-storey drift demands and damage patterns. A better distribution of the damage leads to an increase in global displacement capacity-this is, next to the strength increase, the main advantage of adding RC walls to the URM building. This had also been observed in quasi-static cyclic tests on subassemblies of RC and URM walls (Paparo and Beyer 2014). The RC walls often accommodate stair cases or lift shafts and are therefore often situated at the perimeter of the building. In particular, when RC walls are added as retrofit measures rather than during the initial design process, an even distribution of the RC walls over the floor plan is often difficult to achieve. This was simulated in the test by grouping the two RC walls at the south end of the structure. As a result, the structure displayed a rather different behaviour for the two loading directions, which was reflected in the force-displacement response, the acceleration and drift profiles as well as the out-of-plane response of the URM walls. The displacement capacity of the test unit was limited by the failure of the URM walls. The displacement capacity was smallest for loading towards the north, i.e., when, due to the coupling moment transferred by slabs and spandrels, the axial force in the URM wall increased, leading to a decrease in the displacement capacity (Lang 2002, Petry and Beyer 2014b). The out-of-plane response is only briefly discussed in this paper; more information on the particularities of the out-ofplane response of URM walls in this building typology are presented in Tondelli and Beyer (2014).

It is clear that the beneficial effect of adding RC walls to URM buildings can only be achieved if the strength and stiffness of the two types of walls stand in a certain proportion. At present, models for determining these ratios are currently lacking. Moreover, the analysis of mixed structures is rather sensitive to the assumed stiffness properties of the two types of walls (Paparo and Beyer 2014). To advance the design and analysis of buildings with RC and URM walls, the data of the shake-table test is made publically available. To facilitate the use of the data, next to the raw data set, a data set with postprocessed and derived data is available. A detailed description of the two data sets can be found in the appendix to this paper.

Acknowledgments The research leading to these results received funding from the European Community's Seventh Framework Programme [FP7/2007-2013] for access to TREES laboratory of EUCENTRE under the Grant Agreement No. 227887 (SERIES Project). Additional financial support was received from the Office Fédéral de l'environnement (OFEV) in Switzerland. The reduced-scale bricks were fabricated and donated by Morandi Frères SA, Switzerland. The authors appreciate and gratefully acknowledge all contributions. The authors would like to thank all members of the project team, namely Prof. B. Binici, Dr. C. Butenweg, Prof. M.A. Eberik, Dr. T. Wenk, Dr. P. Lestuzzi, and Dr. J. Varga. The authors are indebted to 
all members of the TREES laboratory and, in particular, the head of the laboratory, Professor A. Pavese, for their invaluable support during the entire duration of the project.

\section{Appendices}

The objective of the appendices is to share the data gained from the shake-table test by documenting and post-processing in such a way that it can be easily used by third parties. The appendices summarise the geometry of the test unit (Appendix 1) and material properties of all construction materials, i.e., mortar, brick, masonry, concrete and reinforcing bars (Appendix 2). Appendix 3 describes the instrumentation of the test unit. Appendix 4 details the two sets of data that can be downloaded via the following link: www.zenodo.org using the doi: 10.5281/zenodo.11578. The two sets of data correspond to (1) the unprocessed data and (2) a set of post-processed data and derived data where the data from the conventional and optical measurement systems employed in the test are synchronised.

\section{Appendix 1: Test unit}

\section{Geometry of the test unit}

The test unit was a four-storey structure with RC and URM walls and was built at halfscale (Fig. 26). The test unit had a rectangular footprint, and the walls—six URM walls and two RC walls-were arranged along the perimeter of the building (Fig. 27).

The testing at reduced scale was conducted following the "Artificial Mass Simulation" law (Krawinkler 1979). This scaling law requires that the stiffness, strength and deformation capacities of the construction materials at reduced scale are the same as those at full-scale and that the density is increased by the scaling factor. However, changing the density without influencing the mechanical properties is typically not feasible, and additional masses were added in the form of concrete blocks casted on top of each slab. Plastic sheets were placed between the additional masses and the slab in order to minimise the blocks' contribution to the stiffness and strength of the floor slabs. Table 3 summarises the masses of the test unit and the shake-table.

The URM walls were constructed using half-scale clay brick units that were specifically produced for the project; the dimension of the brick units were $150 \times 95 \times 95 \mathrm{~mm}$ $(\mathrm{L} \times \mathrm{W} \times \mathrm{H})$. The walls were assembled using standard mortar of class M15; the thickness of the horizontal and vertical mortar joints was also scaled down by a factor of two and was therefore $5 \mathrm{~mm}$ thick. The brick units employed for the construction of the URM walls were selected after an experimental campaign that compared the behaviour of URM walls at full-scale and half-scale (Petry and Beyer 2014a). The experimental campaign included material tests as well as quasi-static cyclic tests on half- and full-scale URM walls. It showed that the half-scale masonry leads to very similar values as the prototype masonry with regard to lateral stiffness, strength and deformation at peak strength but has an ultimate drift capacity (associated with a $20 \%$ drop in horizontal strength) which exceeds that of the full-scale masonry by approximately $10 \%$ (Petry and Beyer 2014a). At axial load failure, the drift capacity of the half-scale masonry was, on average, approximately $40 \%$ larger than that of the full-scale masonry.

Past experience on the scaling of RC members showed that testing at half-scale leads to reasonable results if the bar diameter and the maximum aggregate size are scaled 


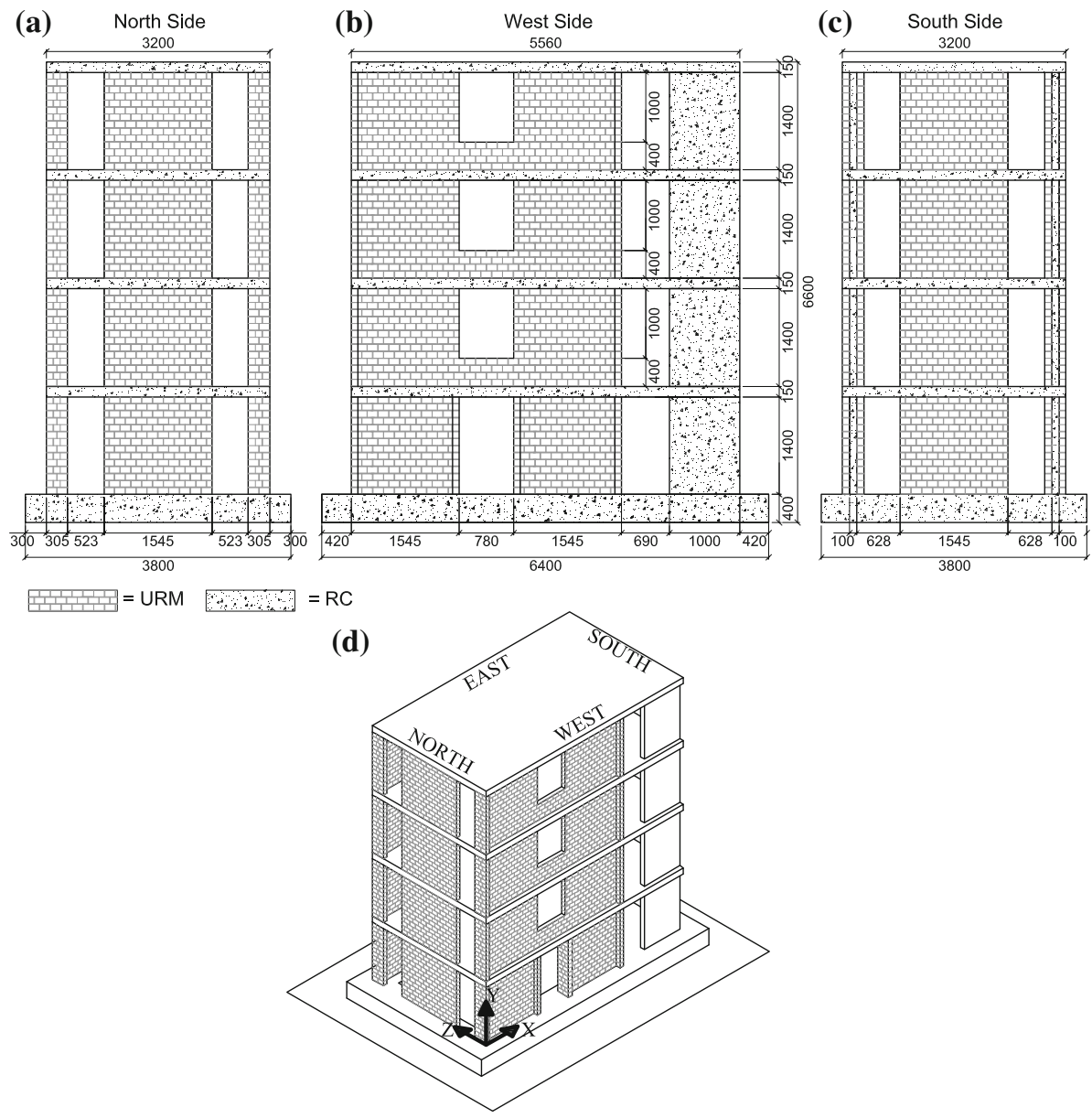

Fig. 26 Views of the test specimen: north side (a), west side (b) south side (c) and definition of the global reference system for the "Post-processed Data" (d). All measures are in $\mathrm{mm}$

accordingly (Haroun et al. 1998; Ohtaki 2000). Typical, standard concrete has a maximum aggregate size of $32 \mathrm{~mm}$. For the casting of half-scale members, the maximum aggregate size should therefore be $16 \mathrm{~mm}$. To ease the pumping of the concrete, a maximum aggregate size of $8 \mathrm{~mm}$ was used instead. It is expected to have no impact on the obtained results, as the RC walls underwent only very limited ductility demands, the crack widths were small and the walls did not fail.

The two RC walls had the same geometry and reinforcement layout (Fig. 28). The RC slabs were $150 \mathrm{~mm}$ thick. The top and bottom reinforcement of the slab consisted of a steel net with D10 $\mathrm{mm}$ bars at $100 \mathrm{~mm}$ spacing.

\section{Construction and transportation}

The test unit was built between September and October 2012 outside the TREES laboratory of EUCENTRE. The construction started with the casting of the RC ring foundation. For each of the four stories, first the six URM walls were built. Then, the 


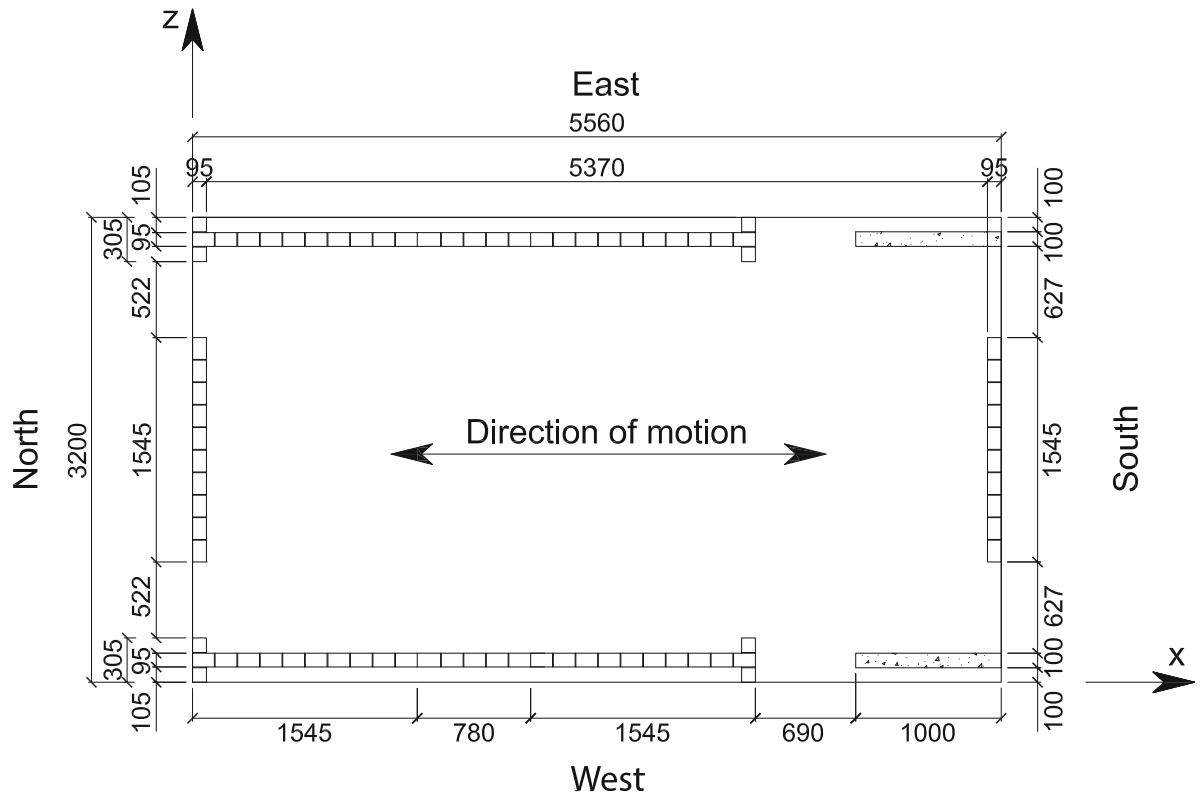

Fig. 27 Test specimen: plan view; all measures are in $\mathrm{mm}$

Table 3 Summary of structural masses

\begin{tabular}{ll}
\hline Foundation & $13.1 \mathrm{t}$ \\
Mass of the structure & $34.9 \mathrm{t}$ \\
Additional masses & $34.9 \mathrm{t}$ \\
Total mass & $82.9 \mathrm{t}$ \\
Total mass without foundation & $69.8 \mathrm{t}$ \\
Total mass during transportation & $48.0 \mathrm{t}$ \\
Mass of the shake-table & $42.0 \mathrm{t}$ \\
\hline
\end{tabular}

reinforcement cages of the RC walls and slab were prepared, and finally, the walls and slabs were casted simultaneously.

The transportation of the specimen from the construction area to the shake-table was performed 28 days after the last casting of concrete. The structure was lifted by means of four hydraulic jacks and then moved using a slider system. In order to prevent cracking during the transportation, all URM walls were post-tensioned by two high-strength steel bars connecting the foundation to a steel beam at the top of each URM wall. The test unit was placed onto the shake-table, the foundation ring was post-tensioned to the shake-table and the post-tensioning system of the URM walls was removed. A visual inspection and a comparison of ambient noise vibration measurements before and after the transportation showed that the structure had not suffered any damage during the transportation. Before instrumenting the structure, the additional masses were casted with an uniform thickness equal to $430 \mathrm{~mm}$; the layout of the additional masses over the RC slabs is presented in Fig. 29. 


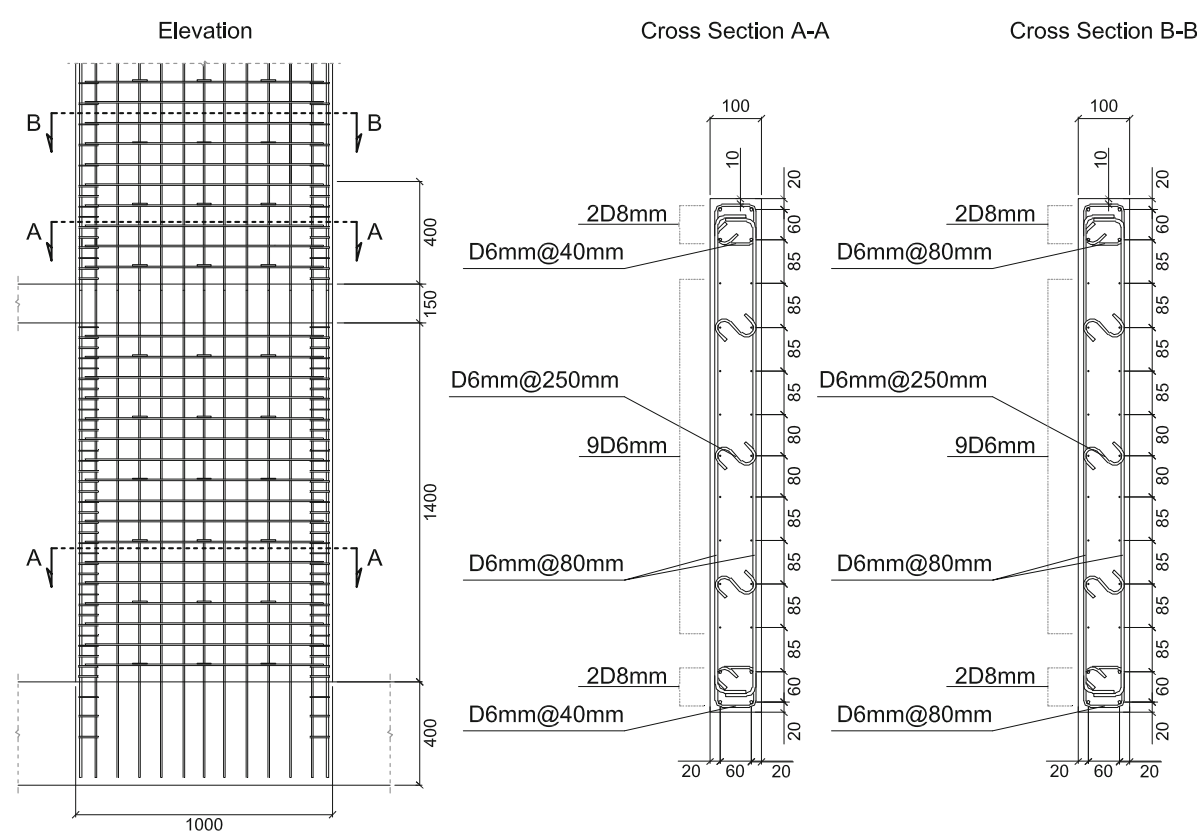

Fig. 28 Reinforcement layout of RC walls: elevation (left) and cross sections (right); all measures are in $\mathrm{mm}$

\section{East}

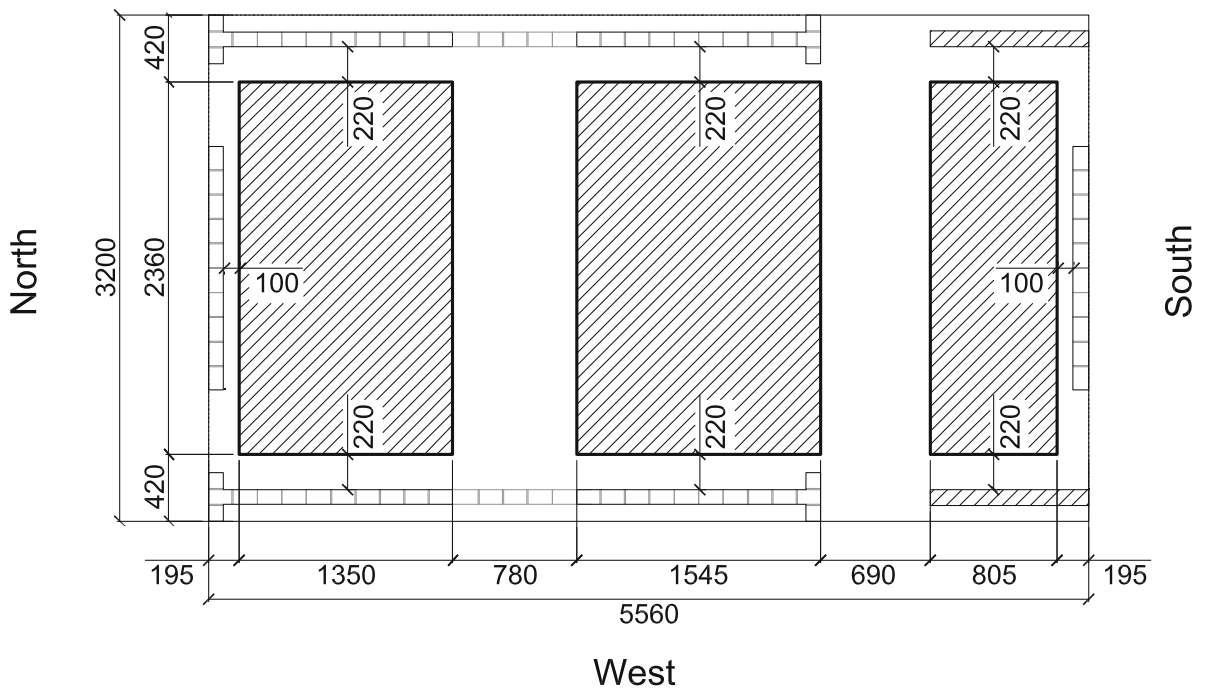

Fig. 29 Additional masses: plan view of the layout; all measures are in $\mathrm{mm}$ 


\section{Appendix 2: Material properties}

\section{RC elements}

$\mathrm{RC}$ walls and slabs were casted using a concrete of class C28/35 and steel reinforcement of class B450C according to the classification of CEN (2004a). The RC foundation was casted using the same steel class and concrete of class C40/50. To investigate the mechanical properties of the concrete and steel, compression tests on cubic and cylindrical concrete samples and tensile tests on steel bars were conducted.

During each cast, nine concrete cubic samples were collected. The cubes with side lengths of $150 \mathrm{~mm}$ were used to determine the cubic strength $\left(f_{\text {cm,cube }}\right)$ according to UNI EN 12390-3 (2003). They were tested approximately five months after the casting, i.e., approximately two months after the testing of the building. Additionally, when casting the second storey, five cylindrical samples with a diameter of $160 \mathrm{~mm}$ and height of $320 \mathrm{~mm}$ were collected. Three of the cylinders were used to determine the elastic modulus of the concrete $\left(E_{c m}\right)$ according to UNI 6556 (1976) and the cylindrical strength $\left(f_{c m}\right)$. The remaining two cylinders were used for determining the concrete tensile strength $\left(f_{c t m}\right)$ by means of "double-punch" tests. These tests are carried out on cylinder samples which had been cut at half-height (Chen 1970). All the compression tests were performed in the laboratory of the Department of Civil Engineering and Architecture of the University of Pavia, while the "double-punch" tests were performed in the laboratory of the Institute of Civil Engineering at EPFL. Table 4 reports the results from the concrete tests; for each parameter, the mean value and the coefficient of variation are given.

For the construction of RC walls, only bars of 6 and $8 \mathrm{~mm}$ diameter were used. For each diameter, five bar samples-500 $\mathrm{mm}$ long-were subjected to tensile tests to determine their yield strength $\left(f_{y}\right)$ and tensile strength $\left(f_{t}\right)$. The same test was performed on five samples of the steel net used for the reinforcement of the RC slabs. The tensile test on straight samples was performed according to UNI EN ISO 15630-1 (2010), while the test on the steel net samples was performed following the Standard UNI EN ISO 15630-2 (2002). All tests on steel samples were performed in the laboratory of the Department of Civil Engineering and Architecture of the University of Pavia, and the results of these tests are summarised in Table 5.

Table 4 Results from the compression tests and from double-punch tests on concrete samples

\begin{tabular}{|c|c|c|c|c|c|c|c|c|}
\hline & \multicolumn{2}{|c|}{$\begin{array}{l}\text { Compressive strength } \\
\text { (cubes) }\end{array}$} & \multicolumn{2}{|c|}{$\begin{array}{l}\text { Compressive } \\
\text { strength (cylinders) }\end{array}$} & \multicolumn{2}{|c|}{ Elastic modulus } & \multicolumn{2}{|c|}{ Tensile strength } \\
\hline & $\begin{array}{l}f_{c m, c u b e} \\
(\mathrm{MPa})\end{array}$ & $\begin{array}{l}\mathrm{COV} \\
(\%)\end{array}$ & $\begin{array}{l}f_{c m} \\
(\mathrm{MPa})\end{array}$ & $\begin{array}{l}\mathrm{COV} \\
(\%)\end{array}$ & $\begin{array}{l}E_{c m} \\
(\mathrm{GPa})\end{array}$ & $\begin{array}{l}\text { COV } \\
(\%)\end{array}$ & $\begin{array}{l}f_{\text {ctm }} \\
(\mathrm{MPa})\end{array}$ & $\begin{array}{l}\mathrm{COV} \\
(\%)\end{array}$ \\
\hline Foundation & 59.84 & \pm 4 & - & - & - & - & - & - \\
\hline Storey 1 & 45.33 & \pm 3 & - & - & - & - & - & - \\
\hline Storey 2 & 43.07 & \pm 3 & 44.24 & \pm 2 & 24.06 & \pm 1 & 2.65 & \pm 2 \\
\hline Storey 3 & 37.45 & \pm 4 & - & - & - & - & - & - \\
\hline Storey 4 & 31.30 & \pm 7 & - & - & - & - & - & - \\
\hline
\end{tabular}


Table 5 Results from the tensile test on steel samples

\begin{tabular}{llllll}
\hline & \multicolumn{2}{l}{ Yield strength } & & \multicolumn{2}{l}{ Ultimate strength } \\
\cline { 2 - 3 } & $f y(\mathrm{MPa})$ & $\operatorname{COV}(\%)$ & & $f t(\mathrm{MPa})$ & $\operatorname{COV}(\%)$ \\
\hline$\phi 6 \mathrm{~mm}$ & 530 & \pm 2 & & 633 & \pm 1 \\
$\phi 8 \mathrm{~mm}$ & 532 & \pm 4 & & 629 & \pm 3 \\
Net & 491 & \pm 2 & & 611 & \pm 2 \\
\hline
\end{tabular}

\section{URM elements}

The characterisation of the URM was comprised different types of material tests. First, mortar samples were collected during the construction of both the shake-table test unit and the masonry wallets for material tests. Second, tests on masonry wallets and triplets were carried out to determine the masonry properties. More than one hundred mortar samples were collected during the construction of the URM walls; these samples in the form of prisms $(160 \times 40 \times 40 \mathrm{~mm})$ were subjected to three-point bending tests for the definition of the flexural strength $f_{t m}$, and the two fragments were then used for compression tests to determine the cube mortar strength $f_{m}$. The tests were performed in the laboratory of the Department of Civil Engineering and Architecture of the University of Pavia according to UNI EN 1015-11 (1999). The results of these mortar tests are summarised in Table 6.

As outlined in Sect. 5.1, prior to the construction of the shake-table test unit, a separate campaign studied the effect of scaling on masonry (Petry and Beyer 2014a). Next to quasistatic cyclic tests, the following material tests were performed at the laboratory of the Institute of Civil Engineering at EPFL (Fig. 30): compression tests (CEN 2002), diagonal compression tests (RILEM 1991) and shear triplet tests (CEN 2007). The results are reported in Tables 7, 8 and 9 to complement the mortar tests performed at the University of Pavia. The URM wallets for these material tests were built using half-scale model bricks from the same batch as those used for the construction of the shake-table test unit. For logistical reasons, the mortar was obtained from a different producer but was also classified as M15. For comparison, the compression strength of the mortar used for the construction of the wallets is reported in Table 10. The obtained mortar-strength values correspond well to the mortar strengths of the first- and second-storey URM walls of the shake-table test unit, i.e., to those two stories that underwent the largest inelastic deformations (Table 6).

The compression tests on masonry wallets were used to determine the compression strength $\left(f_{u}\right)$, the Poisson's ratio $v$ and the elastic modulus $E$ of the masonry for vertical compression. The latter was evaluated for different stress ranges. The Poisson's ratio was evaluated between 0 and $1 / 3$ of the peak strength.

Table 6 Results from three-point bending test and compression test on mortar samples from test unit

\begin{tabular}{|c|c|c|c|c|c|}
\hline & \multirow{2}{*}{$\begin{array}{l}\text { Number of prisms } \\
\mathrm{N}(-)\end{array}$} & \multicolumn{2}{|c|}{ Flexural tensile strength } & \multicolumn{2}{|c|}{ Compressive strength } \\
\hline & & $f_{t m}(\mathrm{MPa})$ & $\operatorname{COV}(\%)$ & $f_{m}(\mathrm{MPa})$ & $\operatorname{COV}(\%)$ \\
\hline Storey 1 & 18 & 3.16 & \pm 28 & 10.85 & \pm 40 \\
\hline Storey 2 & 21 & 3.30 & \pm 25 & 10.14 & \pm 31 \\
\hline Storey 3 & 36 & 3.39 & \pm 30 & 10.00 & \pm 34 \\
\hline Storey 4 & 30 & 2.62 & \pm 42 & 7.04 & \pm 54 \\
\hline Whole Structure & 105 & 3.03 & \pm 32 & 9.07 & \pm 42 \\
\hline
\end{tabular}



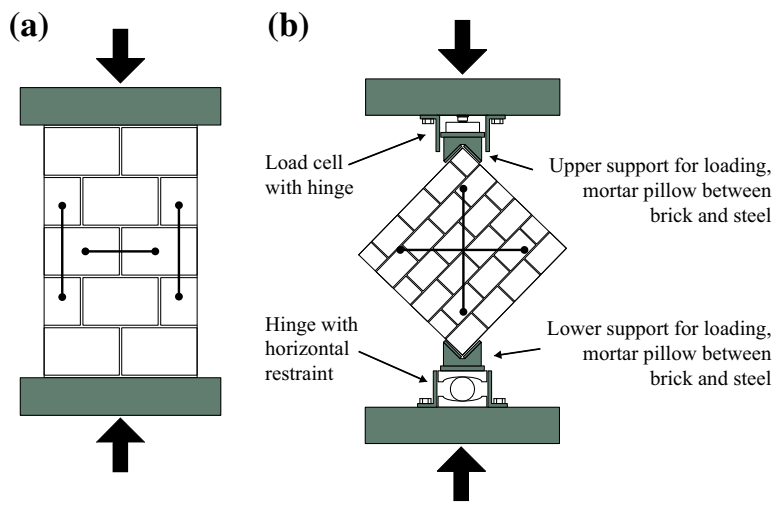

(c)

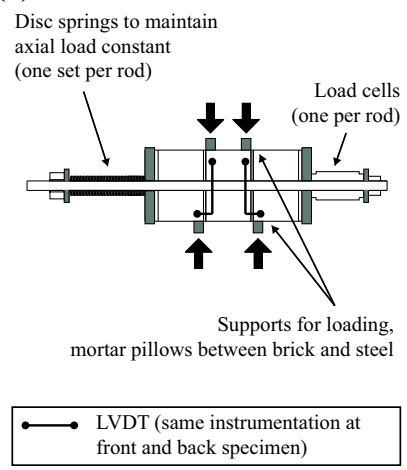

Fig. 30 URM wallets for: a compression test, b diagonal compression test and c shear test (Petry and Beyer 2014a)

Table 7 Compressive strength, Poisson's ratio and E-modulus of masonry from compression tests (Petry and Beyer 2014a)

\begin{tabular}{|c|c|c|c|c|c|c|c|c|}
\hline \multirow{2}{*}{$\begin{array}{l}\text { Number of } \\
\text { samples } \\
\mathrm{N}(-)\end{array}$} & \multicolumn{2}{|c|}{ Compressive strength } & \multicolumn{2}{|c|}{ Poisson's ratio } & \multicolumn{4}{|c|}{ Elastic modulus } \\
\hline & $\begin{array}{l}f_{u} \\
(\mathrm{MPa})\end{array}$ & $\begin{array}{l}\text { COV } \\
(\%)\end{array}$ & $\begin{array}{l}\mathrm{v}_{0-1 / 3} \\
(-)\end{array}$ & $\begin{array}{l}\text { COV } \\
(\%)\end{array}$ & $\begin{array}{l}E_{O-1 / 3} \\
(\mathrm{GPa})\end{array}$ & $\begin{array}{l}\text { COV } \\
(\%)\end{array}$ & $\begin{array}{l}E_{O-3 / 3} \\
(\mathrm{GPa})\end{array}$ & $\begin{array}{l}\text { COV } \\
(\%)\end{array}$ \\
\hline 5 & 5.66 & \pm 4 & 0.20 & \pm 65 & 5.46 & \pm 8 & 4.50 & \pm 9 \\
\hline
\end{tabular}

$E_{0-1 / 3}$ is the secant modulus at $1 / 3$ of the peak strength $\left(f_{u}\right)$ and $E_{0-3 / 3}$ is the secant modulus at peak strength

Table 8 Tensile strength of masonry from diagonal compression test (Petry and Beyer 2014a)

\begin{tabular}{lll}
\hline Number of samples & Diagonal tensile strength & \\
\cline { 2 - 3 } $\mathrm{N}(-)$ & $f_{t u}(\mathrm{MPa})$ & COV $(\%)$ \\
\hline 5 & 0.34 & \pm 15 \\
\hline
\end{tabular}

Table 9 Peak strength of mortar-brick interface from shear triplet tests (Petry and Beyer 2014a)

\begin{tabular}{lll}
\hline $\begin{array}{l}\text { Number of samples } \\
\mathrm{N}(-)\end{array}$ & $\begin{array}{l}\text { Cohesion } \\
c(\mathrm{MPa})\end{array}$ & $\begin{array}{l}\text { Friction coefficient } \\
\mu(-)\end{array}$ \\
\hline 10 & 0.23 & 0.70 \\
\hline
\end{tabular}

Table 10 Mortar strength of mortar used for the construction of the masonry wallets (Petry and Beyer 2014a)

\begin{tabular}{|c|c|c|c|c|c|}
\hline & \multirow{2}{*}{$\begin{array}{l}\text { Number of samples } \\
\mathrm{N}(-)\end{array}$} & \multicolumn{2}{|c|}{ Flexural strength } & \multicolumn{2}{|c|}{ Compressive strength } \\
\hline & & $f_{t m}(\mathrm{MPa})$ & $\operatorname{COV}(\%)$ & $f_{m}(\mathrm{MPa})$ & $\operatorname{COV}(\%)$ \\
\hline Wallets for compression tests & 3 & 3.57 & \pm 19 & 13.95 & \pm 5 \\
\hline Wallets for diagonal tensile tests & 6 & 3.36 & \pm 7 & 13.68 & \pm 9 \\
\hline Wallets for shear triplet tests & 6 & 3.23 & \pm 19 & 12.97 & \pm 6 \\
\hline
\end{tabular}




\section{Appendix 3: Instrumentation}

The instrumentation of the test unit was as follows: 20 accelerometers, 8 wire potentiometers, 41 potentiometers, 24 omega gages and an optical measurement system that recorded the displacements of 492 markers on the URM walls of the west face. In the following, the instrumentation setup is described, and figures show the location and orientation of all instruments. Accelerometers are annotated by "Acc", potentiometers by "Pot", and omega gages by "OG". The data recorded by these conventional instruments was recorded with a sampling frequency of $1024 \mathrm{~Hz}$, while the optical measurement system recorded data with a sampling frequency of $60 \mathrm{~Hz}$. The two sets of data were recorded with two independent systems and were therefore not synchronous as raw data sets but were synchronised when post-processing the data.

\section{Accelerometers}

Each concrete slab was instrumented with four accelerometers, two in the longitudinal direction (i.e., the direction of motion) and two in the transversal direction. In addition, three accelerometers were installed on the foundation of the building: The two on the north side recorded accelerations in the longitudinal direction ("Acc_2" and "Acc_3") and the one on the south side in the transversal direction ("Acc_4"). One other accelerometer was installed on the shake-table, recording accelerations in the longitudinal direction ("Acc_1"). Figure 31 shows the layout of accelerometers on the foundation and shaketable as well as on the first-storey slab; the configuration on the other three slabs was identical to that of the first-storey slab. The complete arrangement of the accelerometers is presented in Fig. 32; in both figures, the arrows indicate the positive direction of the unprocessed readings.

\section{Potentiometers}

The potentiometers were employed for two main purposes: measuring the in-plane deformations of the east RC and URM walls of the first storey and measuring the deformations of the out-of-plane loaded URM walls at the second, third and fourth storey.

The RC wall of the first storey on the east side of the building was instrumented with four wire potentiometers (measurement range $\pm 50 \mathrm{~mm}$ ) measuring the diagonal deformations of the top and bottom half of the panel (Fig. 33). Two wire potentiometers at the base were connected to the foundation of the building, while the two at the top were attached to the bottom face of the first-storey slab. In addition, each short side of the wall was instrumented with four potentiometers $( \pm 12.5 \mathrm{~mm})$ covering the whole height of the wall. All potentiometers had an equal base length of $350 \mathrm{~mm}$, and the top and bottom instruments were connected to the foundation and first-storey slab, respectively. For all potentiometers, positive measurement values corresponded to an elongation of the instruments.

Both first-storey URM walls on the east side of the building were instrumented with two wire potentiometers $( \pm 50 \mathrm{~mm})$ covering the two diagonals of the panels (Figs. 34, 35). As in the case of the RC walls, the potentiometers were connected to the foundation and the first-storey slab, and positive measurement values corresponded to an elongation of the instrument. 
(a)

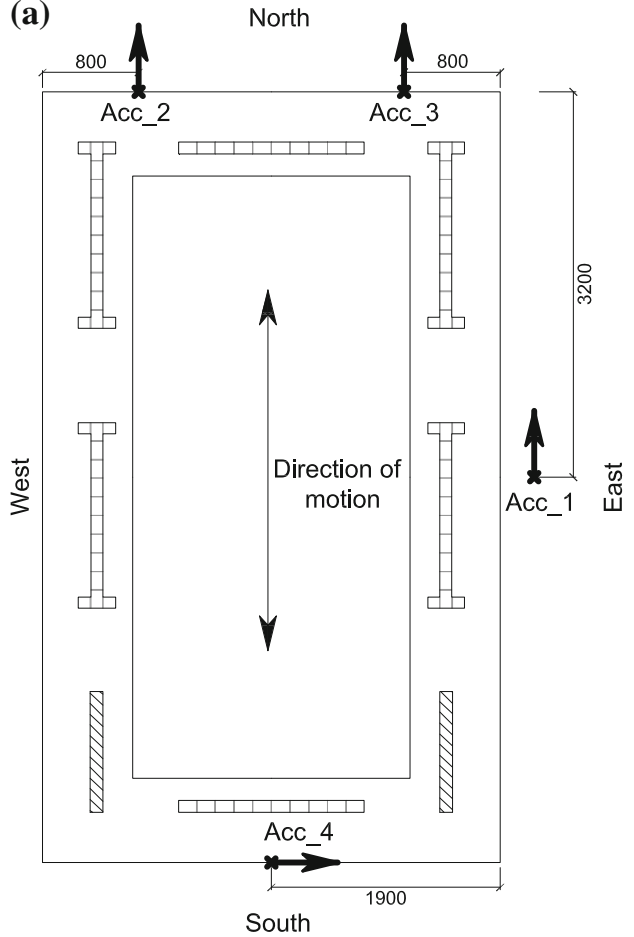

(b)

North

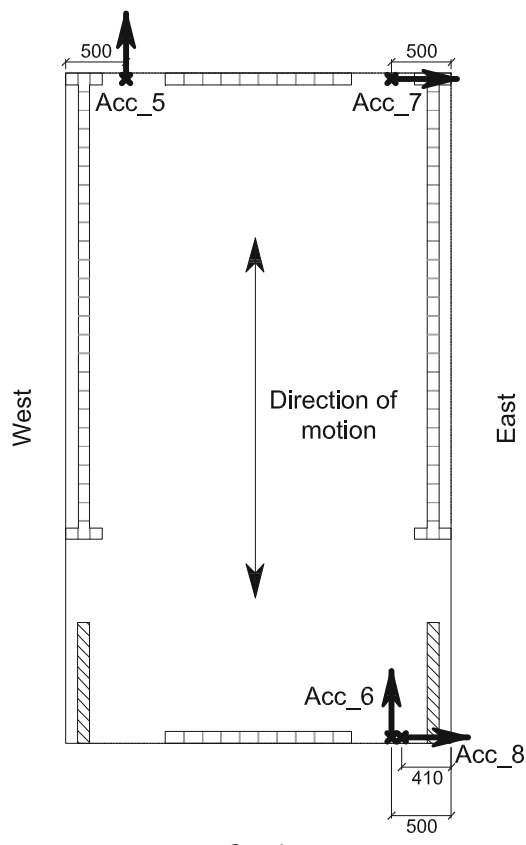

Fig. 31 Configuration of accelerometers: plan view of the foundation (a) and 1st storey slab (b); all measures are in $\mathrm{mm}$

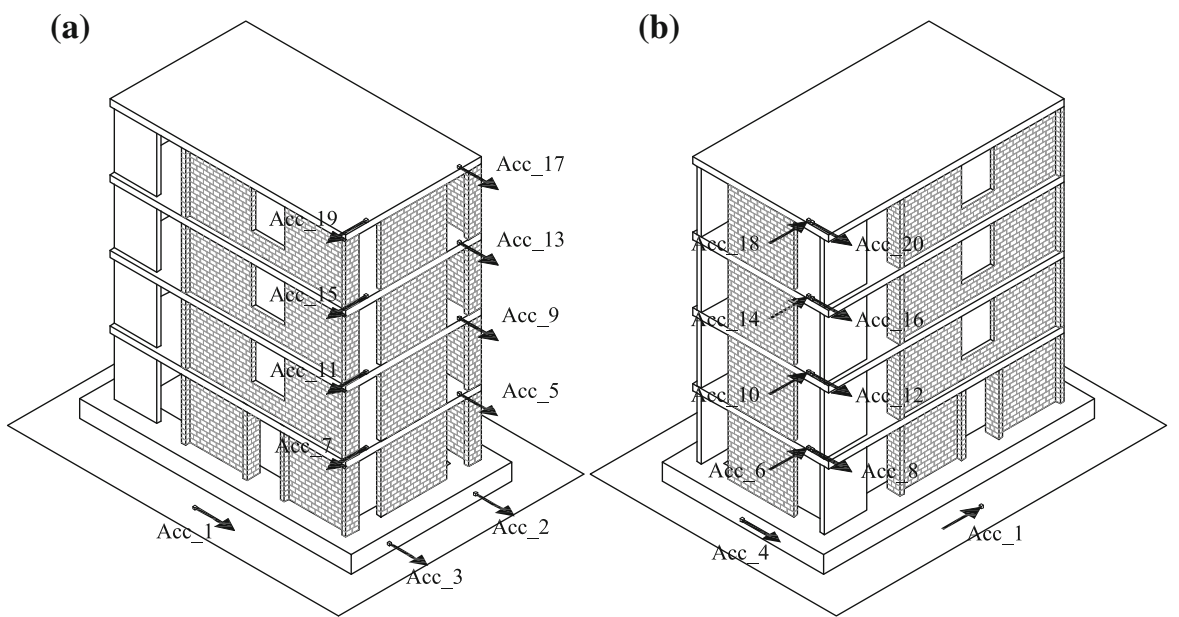

Fig. 32 Configuration of accelerometers: northeast view (a) and southeast view (b)

Two potentiometers $( \pm 12.5 \mathrm{~mm})$ were installed to record possible relative displacements between the foundation of the building and the shake-table. The two potentiometers were labelled "Pot_9" and "Pot_10" and were installed on the east and west sides of the 
a)
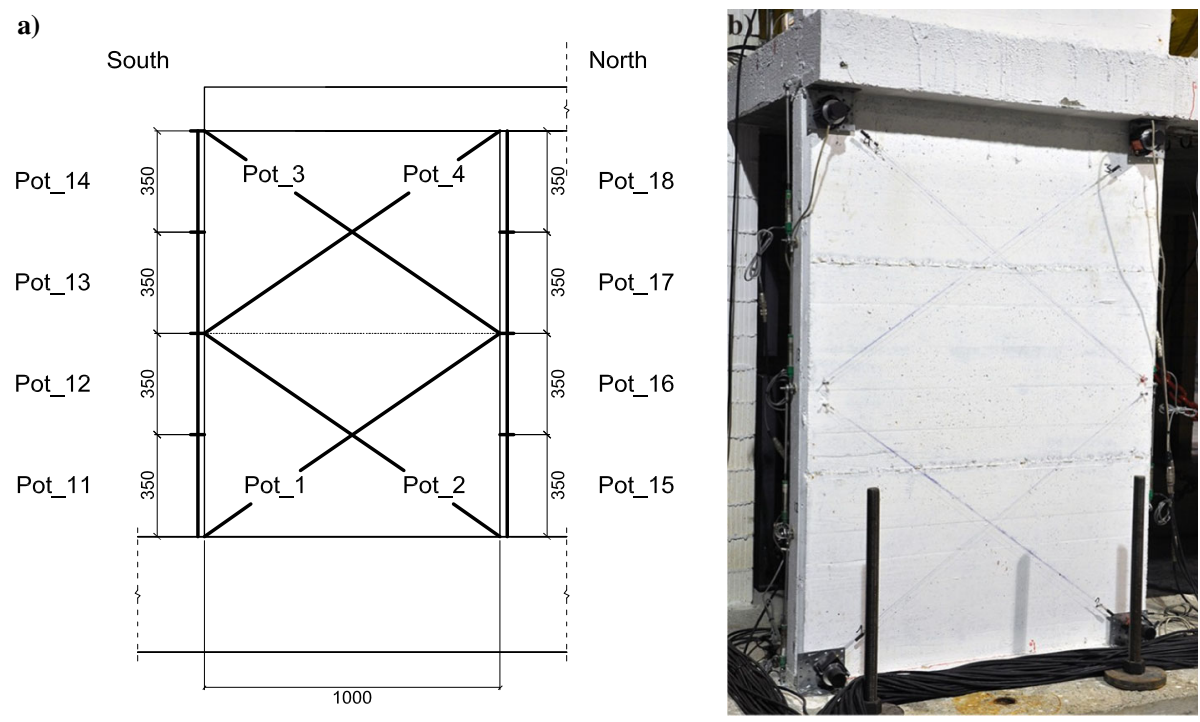

Fig. 33 Potentiometers on the first-storey RC wall on the east side of the structure: layout (a) and image of the wall (b); all measures are in $\mathrm{mm}$

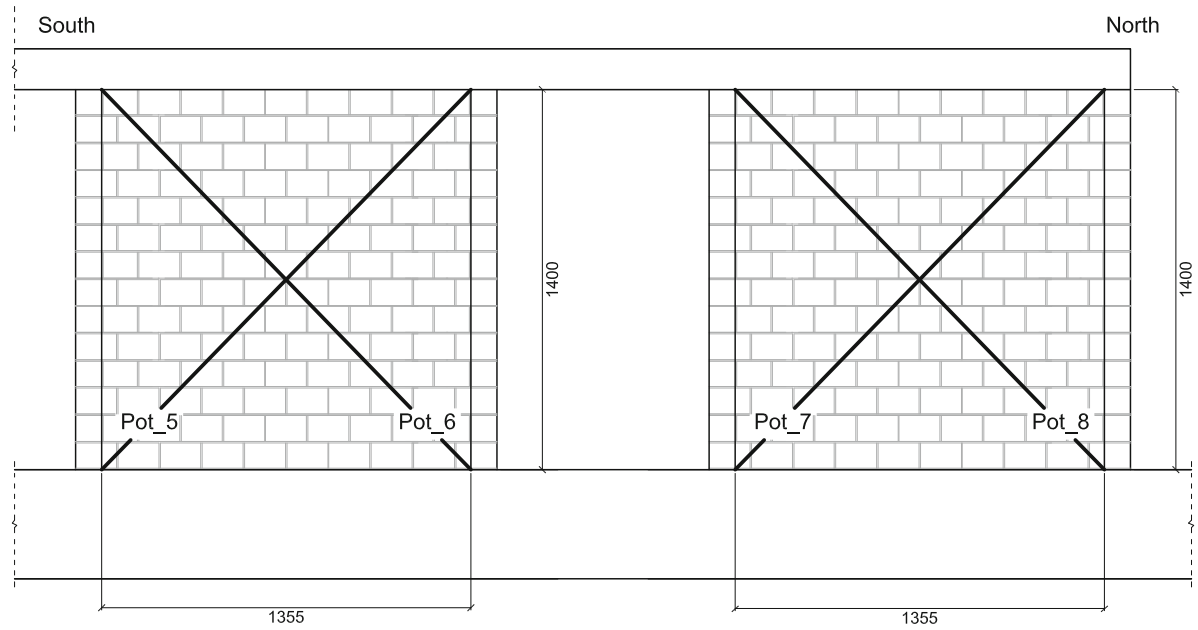

Fig. 34 Configuration of potentiometers on the first-storey URM walls on the east side of the structure; all measures are in $\mathrm{mm}$

foundation. The orientation of the two instruments was such that for "Pot_9", positive values indicated a sliding of the foundation towards the north, and for "Pot_10", positive values indicated a sliding towards the south. One further potentiometer "Pot_49" $( \pm 250 \mathrm{~mm})$ was connected to the floor of the laboratory and the shake-table to measure the displacement of the table. The values recorded by this potentiometer were positive for displacements towards the north.

Each of the out-of-plane loaded URM walls of the second, third and fourth storey was instrumented with five potentiometers. On the top and bottom row of bricks, two 

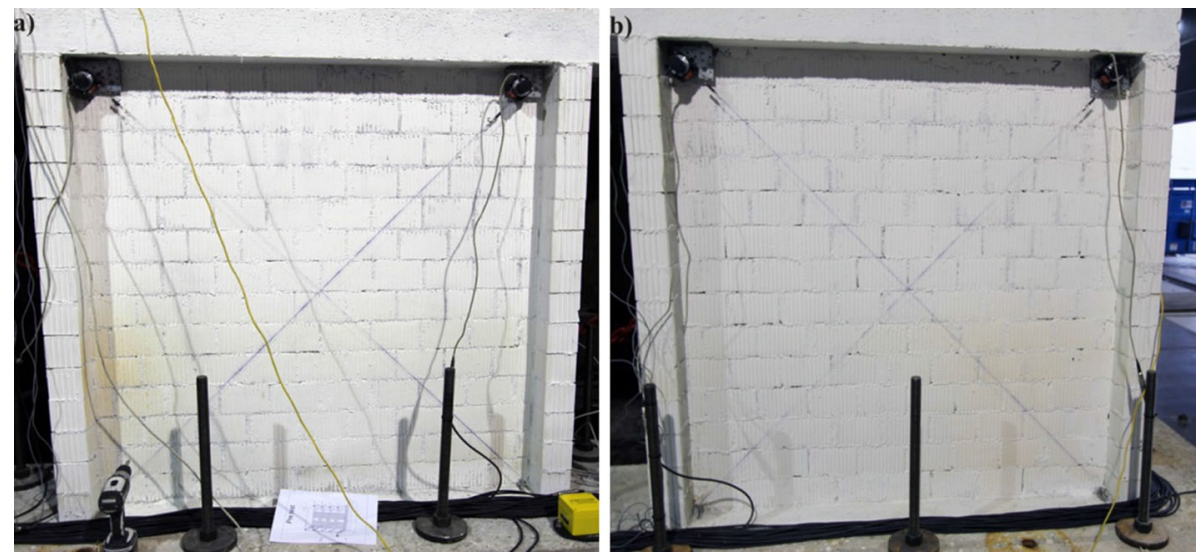

Fig. 35 Configuration of potentiometers on the first-storey URM walls on the east side of the structure: southeast wall (a) and northeast wall (b)
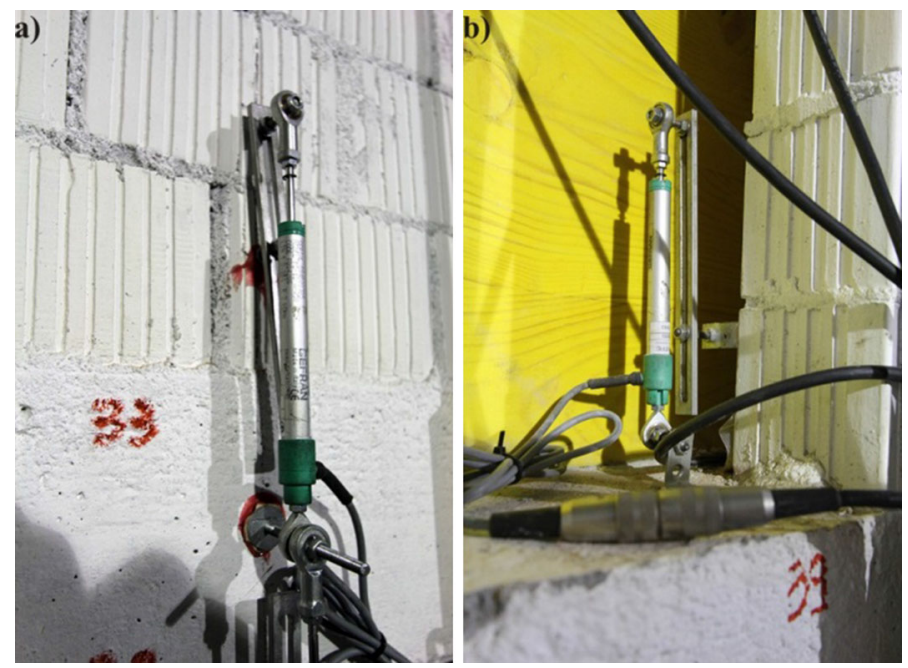

Fig. 36 Potentiometers measuring the relative rotation between slab and out-of-plane loaded wall: "Pot_33" (a) and "Pot_39" (b) measuring base rotation of the third-storey URM walls on the north face of the building

potentiometers $( \pm 25 \mathrm{~mm})$ were installed to measure vertical displacements. From these measurements, the relative rotation of the top and bottom of the wall with respect to the slabs could be computed. Figure 36 shows as example the two potentiometers "Pot_33" and "Pot_39" measuring the internal and external vertical displacement of the bottom row of bricks at the third story on the north side of the building. One further potentiometer $( \pm 125 \mathrm{~mm})$ measured the out-of-plane displacement at mid-height of the walls with respect to the bottom slab. The layout of all potentiometers employed for measuring the deformations of the out-of-plane loaded walls is presented in Figs. 37 and 38. For all potentiometers, positive readings correspond to an elongation of the instrument. 


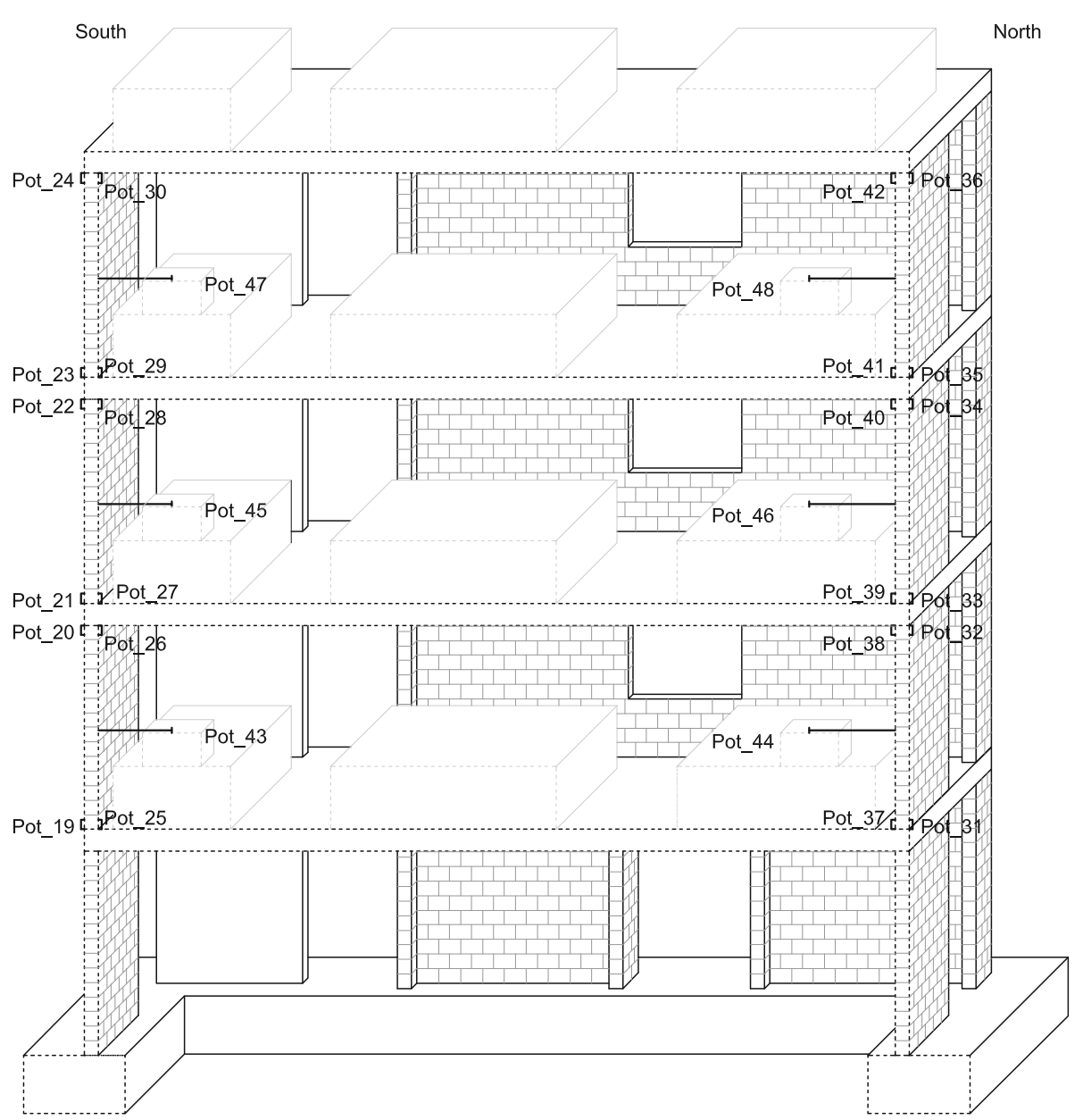

Fig. 37 Potentiometers' configuration for the measure of deformations of the out-of-plane loaded URM walls of the second, third and fourth stories

\section{Omega gages}

One goal of the shake-table test was to investigate the contributing width of the RC slab spanning between vertical walls. For this reason, 24 omega gages were installed on the east side of the first-storey slab to monitor the strains of the top and bottom face of the slab. The omega gages had a base length of $120 \mathrm{~mm}$ and a measurement range of $\pm 2 \mathrm{~mm}$. The layout of the omega gages as well as their labels is presented in Fig. 39. Figure 40 shows a photo of the gages of "Location B". Positive readings corresponded to an elongation of the omega gages.

\section{Optical measurement system}

The displacement response of the structure during the tests was recorded using an optical measurement system. This is a $2 \mathrm{D}$ measurement system, i.e., only displacements in the 


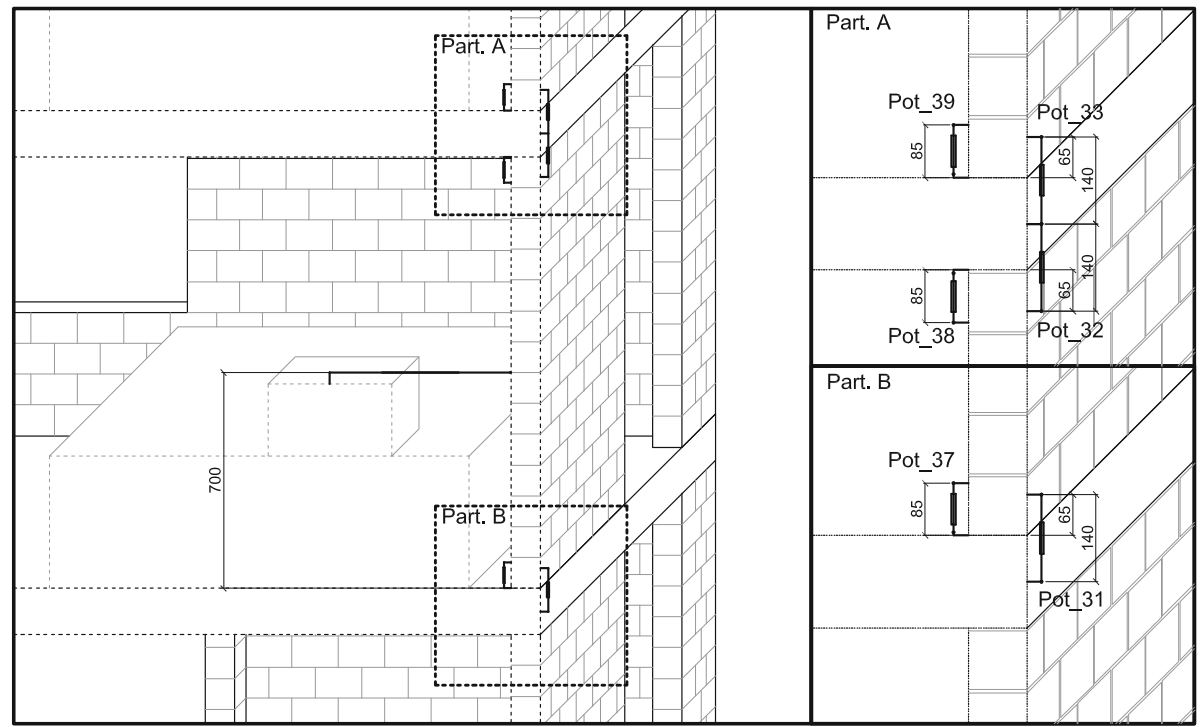

Fig. 38 Potentiometers' configuration for the measure of deformations of the second storey, out-of-plane loaded URM walls on the north face of the building; all measures are in $\mathrm{mm}$

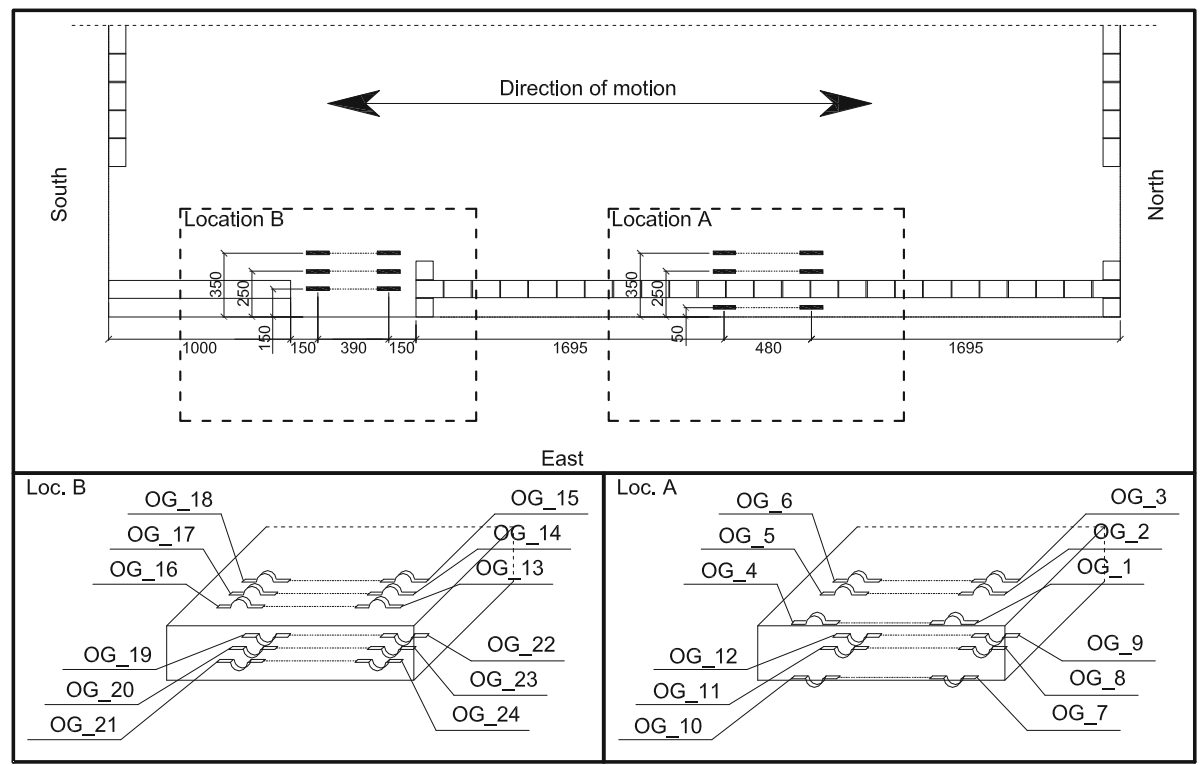

Fig. 39 Configuration of omega gages at the first-storey slab on the east side of the test unit; all measures are in $\mathrm{mm}$

direction of motion and vertical displacements were recorded. This system was developed by the TREES-laboratory (Lunghi et al. 2012) and uses high definition cameras to compute the position of reflecting markers (Fig. 41). Ten cameras were used, each one was equipped with a near-infrared filter and an infrared lamp projecting light against the 

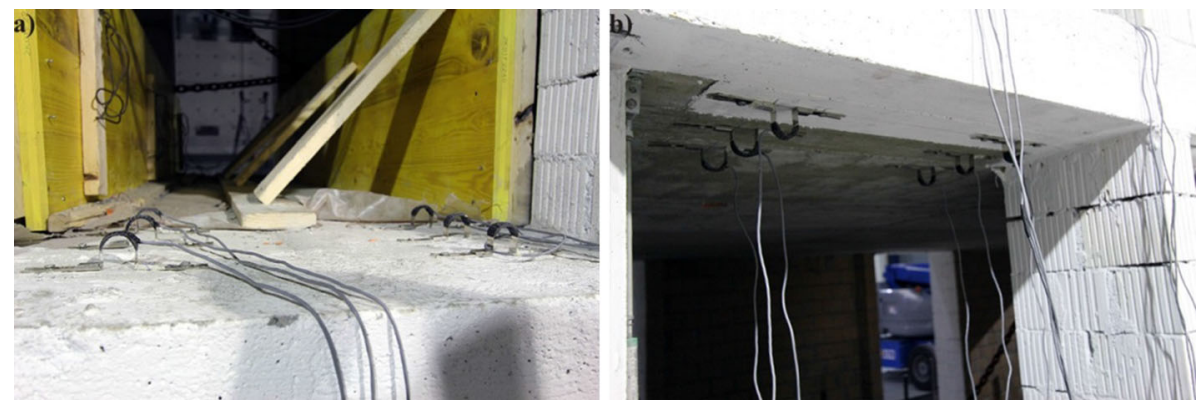

Fig. 40 Omega gages of "Location B": top face of the slab (a) and bottom face (b)
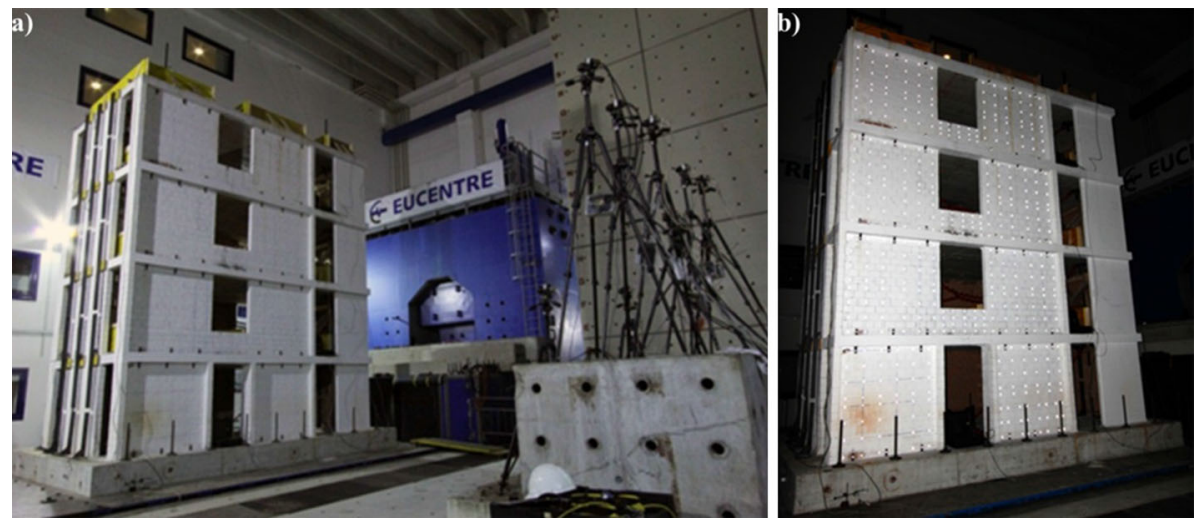

Fig. 41 Optical measurement system: high definition cameras (a), marker distribution on the west façade of the building (b)

reflecting markers. The cameras then recorded the light reflected from the markers with a sampling rate of $60 \mathrm{~Hz}$. Each camera was able to cover a rectangular surface area of approximately $1.5 \mathrm{~m} \times 2 \mathrm{~m}$ and could record the position of about 70 markers. During the test, the ten cameras were not synchronised, but the data was synchronised when it was post-processed (Appendix 4). Due to the limited number of cameras, only the motion of the URM walls and spandrels of the west façade could be recorded. Figure 42 shows the marker layout and the surface covered by each camera. The average distance between gridlines was approximately $0.2 \mathrm{~m}$. The markers, with a square label in Fig. 42, are glued directly onto the URM surface, while the markers with a round label are glued onto small "L"-shaped steel plates, which were fixed to the RC slabs or to the foundation. In total, 492 markers were recorded of which 444 were glued onto the masonry and 48 were fixed to slabs and the foundation.

The camera layout was chosen in such a way that several markers were recorded by two cameras. This configuration allows for reconstruction of the displacement profile of the entire URM façade by synchronising the data measured by one camera with the data measured by an adjacent camera. The label of a marker consists of the camera number followed by a number identifying the marker within the subset of markers measured by one camera. The markers recorded by one camera are numbered from left to right, top to 


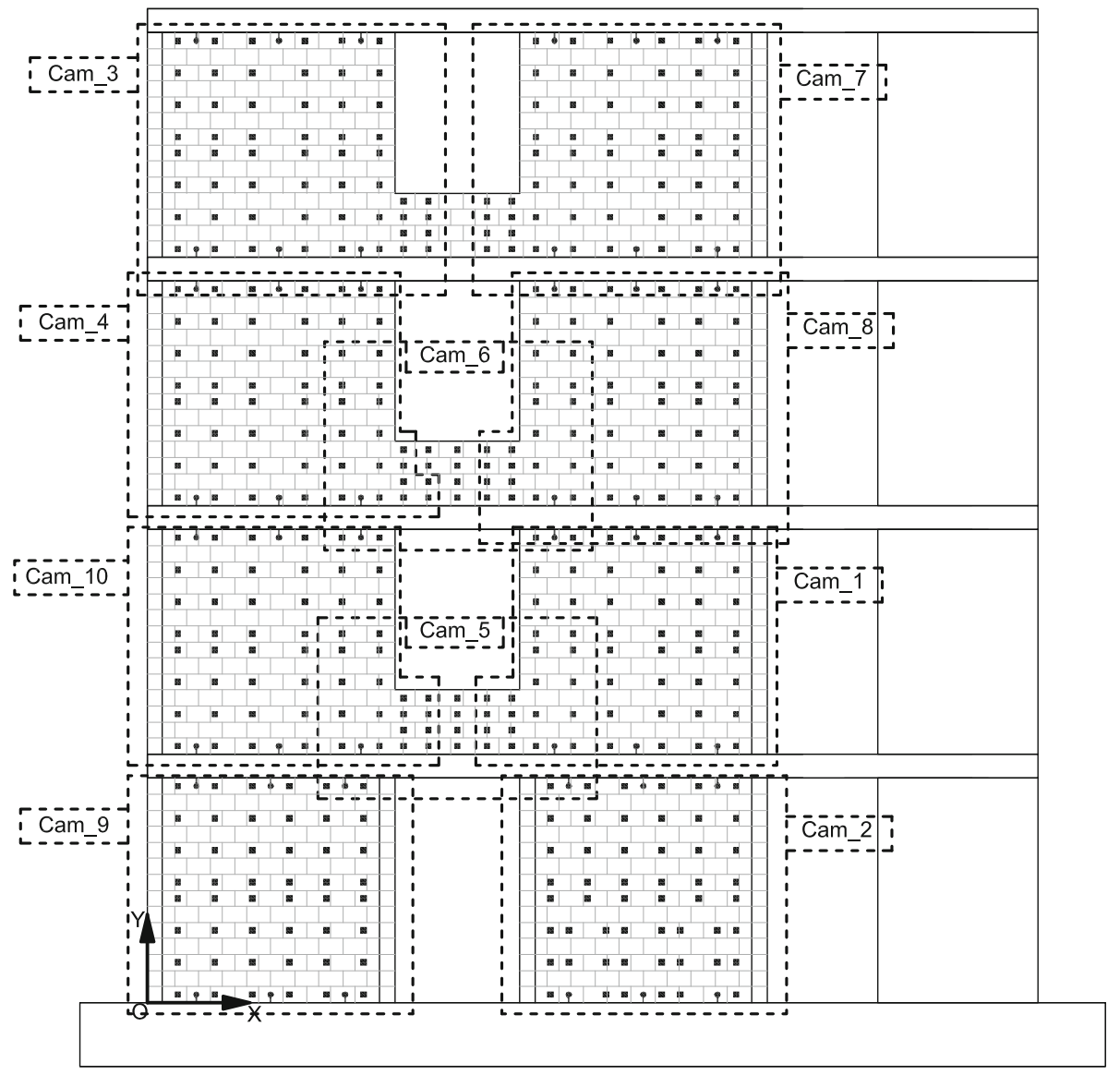

Fig. 42 Optical measurement system: layout of markers and cameras

bottom. Note that the markers belonging to two subsets therefore have two names. The coordinate histories of each marker are computed in a global coordinate system whose origin is located at the initial position of the bottom, left corner of the structure (Lunghi et al. 2012). The x-axis is the horizontal axis and points towards the north, and the y-axis is the vertical axis and points upwards (Fig. 42).

\section{Appendix 4: Test data}

The data can be downloaded as one zip file from www.zenodo.org using the doi: 10.5281/ zenodo.11578 (10 files of 0.26-0.41 GB). The platform ZENODO (www.zenodo.org) was developed under the European FP7 project (http://www.openaire.eu/) and is hosted by the research facility CERN, which operates a Large Hadron Collider. The database is organised into twelve subfolders: "Specimen Level", "Experiment Level", "Signal Level" and nine folders named after each test as follows: "Test<test number $>$ ". Upon unzipping, the folder structure as shown in Fig. 43 unfolds. 


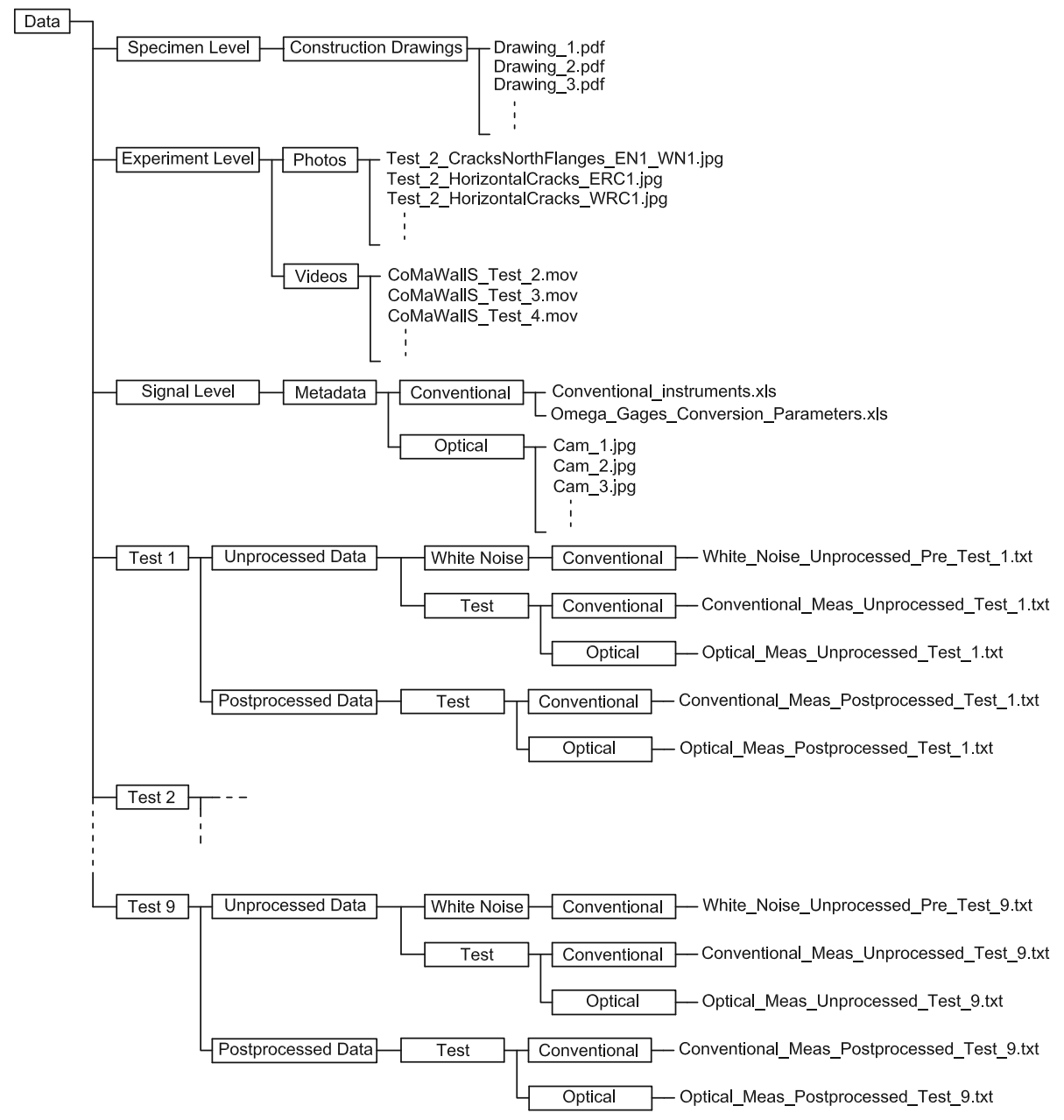

Fig. 43 Organization of the data

The folder "Specimen Level" contains the subfolder "Construction Drawings" with the construction drawings of the test unit as pdf files. The folder "Experiment Level" is organized into two subfolders: "Photos" and "Videos". The folder "Videos" contains the videos recorded during the nine different tests; the files are labelled as follows: CoMaWallS_Test_<test number $>$.mov. Videos are available for all tests except for Test 1 . The folder "Photos" contains pictures taken during the experimental campaign, documenting the damage to the structure. All photos are JPG files, and the file names comprise three components: first, the test number after which the photo was taken; second, the type of damage the picture is documenting; and third, which element of the test specimen is shown on the photo. Figure 44 presents the labelling of the structural elements for the first storey of the structure. Hence, the file Test_2_HorizontalCracks_ERC1.jpg presents the formation of horizontal cracks after Test 2 in the first storey of the east RC wall. The subfolder "Signal Level" contains the subfolder "Metadata" which is organised into the two subfolders "Conventional" and "Optical". The subfolder "Conventional" contains the files 
Fig. 44 Labelling of the structural elements of the first storey

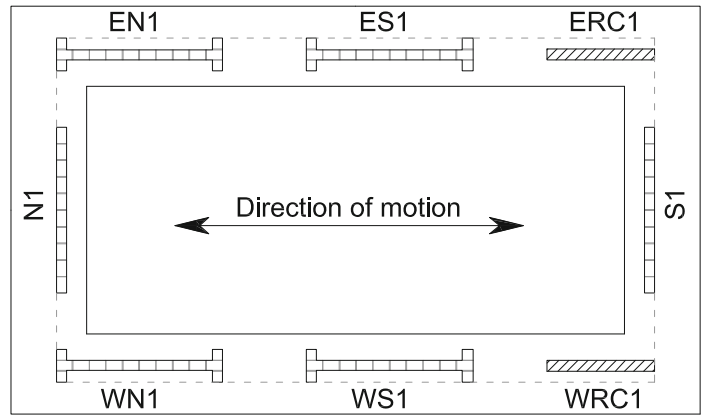

Conventional_Instruments.xls and Omega_Gages_Conversion_Parameters.xls. The first file is organised into six columns, which indicate for each instrument the following information: instrument label, channel number of the instrument in the conventional data files, type of instrument, producing company, model of the instrument and measurement range. The second file contains the parameters for the conversion of the recordings of the omega gages from voltage to deformations. The file comprises three columns. In the first column, the names of all 24 omega gages are listed (see Appendix 3), while the second and third columns report the parameters " $a$ " and " $b$ ". These two parameters are necessary for the definition of the linear relation between the variation of voltage recorded by the gage and its deformation in millimetres (Disp $=a^{*}$ Voltage $+b$ ). The strain is obtained by dividing the displacement by the base length of the instrument (see Appendix 3); positive values of deformation correspond to an elongation of the instrument. The subfolder "optical" contains ten JPG images named after each camera of the optical measurement system. The name of the files are $\mathrm{Cam}_{-}<$camera number $>$.jpg. Each image represents the layout of the markers recorded by the camera and their labels (see Appendix 3).

The data recorded during the nine tests are organised into nine folders, one for each test. Each folder "Test<test number $>$ " is subdivided into two subfolders: "Unprocessed Data" and "Post-processed Data". These folders contain two different types of data: the recordings from conventional instruments (load cell of actuator, accelerometers, potentiometers and omega gages) and the recordings from the optical measurement system. The folder "Unprocessed Data" also contains the white-noise data recorded by the conventional measurement system during the tuning of the shake-table between the tests. These recordings can be used for dynamic identification analysis of the test specimen in order to investigate the variation of the dynamic properties during the test campaign.

\section{Unprocessed data set}

The folder "Unprocessed Data" contains the original and unmodified recorded data from the nine tests and the white-noise measurements recorded between the different tests. The data are organised into two subfolders: "Test" and "White Noise". The folder "Test" is subdivided into the two subfolders "Conventional" and "Optical", which contain the original files recorded during the shake-table testing by the conventional and optical measurement systems. The folder "White Noise" contains only the subfolder "Conventional"; optical measurements were not carried out during the white-noise excitation. The files are column-oriented files, and the different columns are separated by a tabulator ( $(\mathrm{t})$. The numbers are in scientific format with six decimals, and the decimal separator is the dot (.). 


\section{Conventional measurement data}

The file contained in this folder reports the data recorded by the 96 conventional instruments, i.e., accelerometers, potentiometers and omega gages as well as the accelerometer, the displacement transducer and the load cell of the hydraulic actuator of the shake-table. Readings of the latter were exported from the shake-table controller and read into the dataacquisition system of the conventional instruments. The folder contains one file named after the test number as follows: Conventional_Meas_Unprocessed_Test_<test number>.txt. In total, nine files are available, one for each test.

The first line of each file contains the name of the instrument, the second line contains the unit, and from the third line onwards, the recorded data are reported. Each file comprises 97 columns. The first column includes an index which starts for each test with one. It is recalled that the sampling frequency of the conventional instruments was $1024 \mathrm{~Hz}$. Columns 2-4 contain acceleration and displacement of the shake-table and the actuator force. For all three quantities, readings were positive when the table moved towards the north. Columns 5-24 contain the readings of the accelerometers on the shake-table, foundation and test unit; for the labelling of the accelerometers, the reader is referred to Appendix 3. For the "unprocessed" data set, readings are positive for accelerations towards the north (longitudinal direction) and east (transverse direction, Fig. 26). Columns 25-73 and columns 74-97 contain readings from potentiometers and omega gages, respectively. For potentiometers and omega gages, the sign convention of the unprocessed data set was provided in Appendix 3.

\section{White noise conventional measurement data}

Before a test, the shake-table was excited with a white-noise signal (frequency range: $0.2-40 \mathrm{~Hz}$; RMS amplitude: $0.05 \mathrm{~m} / \mathrm{s}^{2}$ ). The white-noise excitation served to tune the shake-table, but the results can also be used to determine the dynamic characteristics of the structure. For this reason, they are included in the unprocessed data set. Note that only the conventional and not the optical measurement system was recording during the white-noise excitation.

The files used for recording the response during the excitation with white noise have the same structure as the ones presented in the previous section. The files are named using the following convention: WhiteNoise_Unprocessed_Pre_Test_<test number $>$.txt. Since this recording was performed between two tests, the suffix "pre-" in the name of the files indicates that the data are recorded prior to a certain test. For example, the file WhiteNoise_Unprocessed_Pre_Test_2.txt reports the white noise data recorded between Tests 1 and 2. In total, eight files are available, and no white noise recordings were carried out prior to Test 7 .

\section{Optical measurement data}

This folder contains one file with the data recorded by the optical measurement system. The file is named Optical_Meas_Unprocessed_Test_<test number $>$.txt. The sampling frequency of the optical measurement system is $60 \mathrm{~Hz}$. In total, nine files, one for each test, are available.

Each file contains the time histories of the $x$ and $y$ coordinates of each marker in the afore-defined global reference system (Fig. 26). The first line of the file reports the name of 
the marker and the coordinate. The column label is composed of a number identifying the camera, a number identifying the marker within the subset of markers measured by this camera and the coordinate ( $x$ or $y$ ). For example, the column named "5.10.x" reports the $x$ coordinate of the 10th marker recorded by Camera 5. The second line of the file reports a variable called "good signal" that indicates if the recorded data for the marker is reliable or not. During the test, a camera may lose contact with the signal coming from one marker; in this case, the software keeps reading a constant coordinate value equal to the last recorded value before the signal was lost. At the end of the test, the software checks if there were markers whose coordinates remained constant during the test for a certain time interval or if there were markers with residual deformations exceeding a certain pre-defined limit value. If the recording of one marker fulfils one of the two conditions, it is considered unreliable. The variable "good marker" is binary, i.e., it takes a value of "one" when the measurements are reliable over the entire duration of the test and "zero" when the measurements are considered to be not fully reliable. The third line reports a variable which takes a value of "one" if the marker was attached to the masonry surface and "zero" if the marker was attached to the foundation or one of the slabs by means of steel angles (Appendix 3). From the fourth line onwards, the measured coordinates are reported.

Each file is composed of 1219 columns; the first column contains an index, and the remaining 1218 columns are the time histories of the horizontal and vertical coordinates of 492 markers; 111 of these 492 markers are measured by two cameras and 3 markers from three cameras.

\section{Post-processed data set}

This final data set contains the post-processed and synchronised conventional and optical data. In addition to the recorded channels, the post-processed data set contains a series of variables that were computed from the original channels; these variables are defined in the following and intended to facilitate the use of the data by allowing the user to easily plot fundamental graphs like global hysteretic response curves. The folder "Post-processed Data" contains the subfolder "Test" which is organised into two subfolders: "Conventional" and "Optical".

The goals of the post-processing were as follows: (1) to obtain a data set in which conventional and optical recordings refer to the same global reference system; (2) to clean the recordings from bias and noise that, for different reasons, had been introduced during the tests; (3) to remove data that are considered unreliable; (4) and to synchronise the measurements coming from the two different systems (conventional and optical).

The synchronisation procedure was based on three steps: first, a re-sampling was made of the optical data from the original sampling frequency of $60 \mathrm{~Hz}$ to the sampling frequency of the conventional measurements of $1024 \mathrm{~Hz}$. Second, the data from the different optical cameras had to be synchronised. Third, the conventional and optical data were synchronised. The synchronisation procedure is presented in the following sections.

The global reference system, which is shown in Fig. 26, follows the reference system of the optical measurement system. The z-axis, which points to the east, was defined by the TREES laboratory as a positive axis for the transverse direction. This sign convention was maintained in the post-processed data, thus leading to a left-handed reference system. Note that the z-axis is only used for the accelerometers that recorded east-west accelerations, which were very small due to the symmetry of the test unit with regard to the north-south axis. Note that the data of the white-noise measurements between tests are not included in the post-processed data set but only in the unprocessed data set. 


\section{Conventional measurement data}

The data contained in the folder "Conventional" are organised into TXT files with the name Conventional_Meas_Postprocessed_Test_<test number $>$.txt. Each file comprises 101 columns as follows: The first column is for the index, columns 2-97 are for the 96 instruments, and columns 98-101 are for derived channels which will be defined later in this section.

The following post-processing procedure was applied to the original data set:

- The sign of the acceleration recordings along the longitudinal direction as well as the read-out from the shake-table controller (acceleration, force and displacement), and the displacement recordings from the potentiometer measuring the displacement of the shake-table ("Pot_49") were switched to match the global reference system.

- Readings of all accelerometers were filtered to remove the noise introduced by the recording instruments. For the filtering, a sixth-order, low-pass Butterworth filter with a cut-off frequency of $40 \mathrm{~Hz}$ was used.

- Due to saturation, some acceleration time histories were showing anomalies such as drifting. These recordings were considered unreliable and were therefore replaced with "NaN" elements ("Not a Number"). If the recordings of an instrument were considered unreliable during a test, the entire channel was replaced with $\mathrm{NaN}$ elements during this test.

- For all tests, the readings of all accelerometers and the read-out from the shake-table controller (acceleration, force and displacement) were shifted to remove the initial offset. The record of each instrument was shifted by subtracting the mean value of the first 500 values of the record.

- For the first test, the readings of potentiometers and omega gages were shifted to remove the initial offset using the procedure described in the previous point. For the other eight tests, the records were shifted so that the initial displacement of a specific test corresponded to the residual displacement of the previous test. The initial value was computed as the mean value of the first 500 readings of the record, and the residual value as the mean value of the last 500 readings. The objective was to eliminate offsets in readings introduced between tests, such as due to accidental movements of the instruments when cracks were marked on the test unit.

- The data recorded by the 24 omega gages were converted from voltage to strain using factors "a" and "b" from the file "Omega_Gage_Conversion_Parameters.xls" previously presented.

\section{Optical measurement data}

The folder "Optical" contains TXT files, one for each test over the different test folders. The file is named Optical_Meas_Postprocessed_Test_<test number $>$.txt. The file has the same format and is organised in the same way as the optical measurement data of the unprocessed data set.

Two modifications were applied to this data set with respect to the unprocessed data set, as follows: first, the data set was re-sampled from the original frequency of $60-1024 \mathrm{~Hz}$, to match the sampling frequency of the conventional data. Second, the data from different cameras were synchronised among each other. The optical measurement system was composed of ten cameras recording different subsets of markers. These cameras, despite having the same sampling frequency, did not take pictures at exactly the same instant and 
therefore the measurements of the different cameras are slightly offset in time. To eliminate this offset, the cameras were synchronised by means of the markers that were recorded by two cameras. To minimize the time lag due to the mixing of signals from different cameras, the signals were synchronised to maximize the cross-correlation coefficient of marker signals that were recorded by more than one camera. In addition, the order of the cameras was chosen to maximize the sum of these computed cross-correlation coefficients.

The adopted synchronisation procedure was the following: first, the cameras of the north-west URM wall were synchronised starting with Cameras 5 and 9 (Fig. 45). To do so, the records of Marker 2A by the two cameras were shifted in time so that the crosscorrelation was maximized. The signals were then padded with $\mathrm{NaN}$-elements at the beginning and end. The synchronisation procedure continued subsequently with Cameras 10, 6, 4 and 3 using the Markers 3A-6A, respectively. The same procedure was then applied to synchronise the cameras recording the south-west URM walls. Finally, the two sets of synchronised data (north-west and south-west) were aligned by synchronising the recordings of Markers $1 \mathrm{~A}$ and $1 \mathrm{~B}$, assuming that the building foundation did not undergo

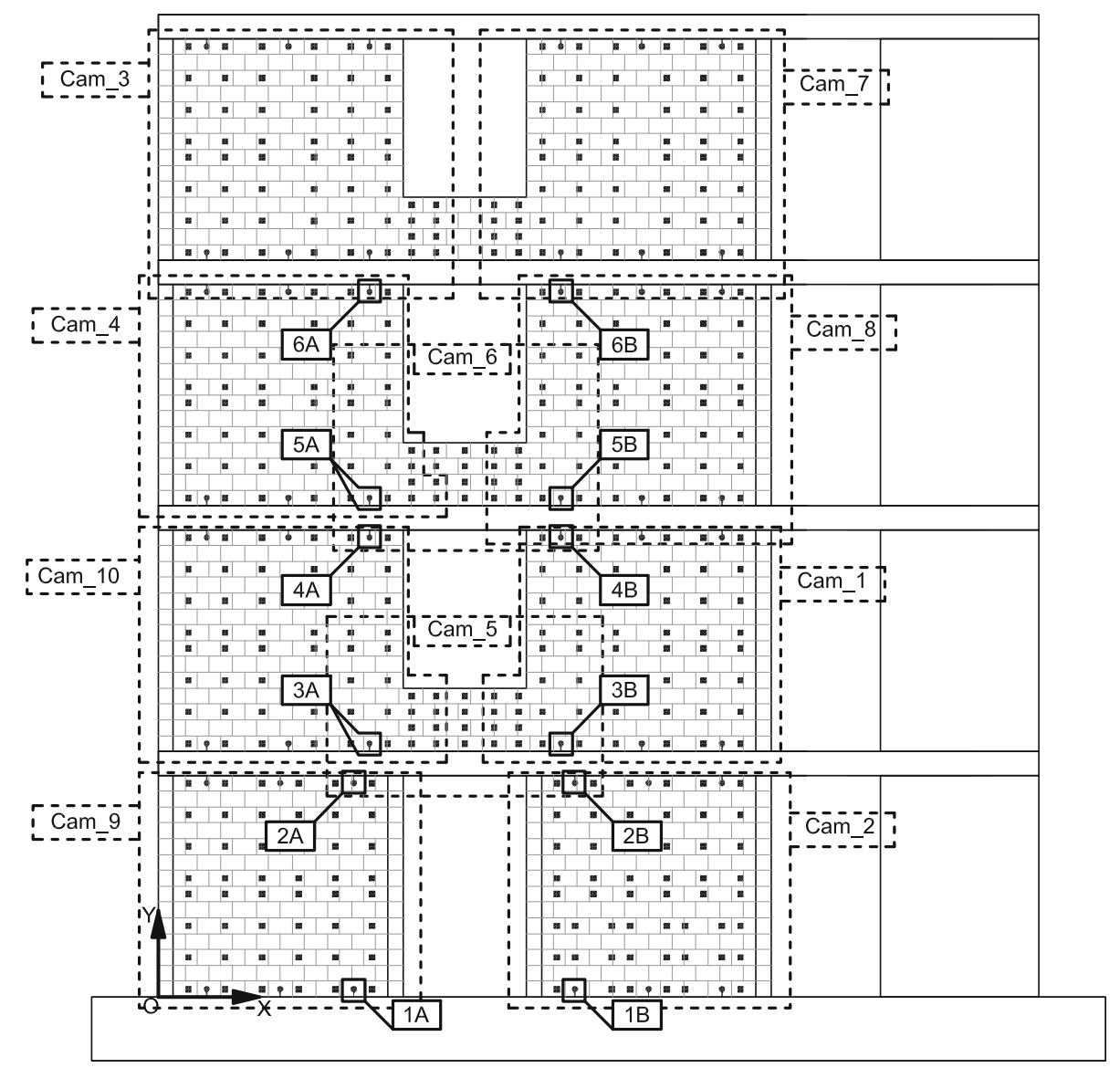

Fig. 45 Definition of the markers for the synchronization of the optical measurement data 
Table 11 Labels of markers that were used for the synchronisation of the cameras

\begin{tabular}{lcclll}
\hline Sync. point & Marker 1 & Marker 2 & Sync. point & Marker 1 & Marker 2 \\
\hline 1A & 9.08 & - & 1B & 2.02 & - \\
2A & 9.53 & 5.02 & 2B & 2.51 & 5.05 \\
3A & 5.08 & 10.08 & 3B & 5.16 & 1.04 \\
4A & 10.61 & 6.02 & $4 \mathrm{~B}$ & 1.55 & 6.05 \\
5A & 6.08 & 4.08 & 5B & 6.16 & 8.13 \\
6A & 4.59 & 3.08 & $6 \mathrm{~B}$ & 8.64 & 7.02 \\
\hline
\end{tabular}

axial deformations during the tests. In Table 11, the correspondence between the point used in the synchronisation procedure, presented in Fig. 45, and the corresponding markers' labelling is presented.

\section{Synchronisation of conventional and optical data}

The conventional and optical data sets were synchronised using a procedure similar to the one presented in the previous section for the synchronisation of the different cameras. For the synchronisation of the two data sets, the displacement histories of the shake-table were used, i.e., the reading of the potentiometer "Pot_49" (see Appendix 3) and the history of the $x$-coordinate of Marker 2B (Fig. 45). The displacement histories were matched in time, maximising the cross-correlation. To apply this procedure, it was necessary to pad records with "NaN" elements at the beginning and at the end.

\section{Derived channels}

The additional channels described in this section are included in the data files for the conventional measurement system. The first derived data channel is Channel 98, which contains an estimate of the base shear $V_{b, A C C}$ of the test unit. The base shear is computed as the sum of the inertia forces of the four stories. The inertia forces of each storey are computed from the two accelerometers that measure accelerations in the longitudinal direction: at Storey 1 from "Acc_5" and "Acc_6", at Storey 2 from "Acc_9" and "Acc_10", at Storey 3 from "Acc_13" and "Acc_14" and at Storey 4 from "Acc_17" and "Acc_18". The unit of the accelerometer readings is g. The inertia force, in $\mathrm{kN}$, was then computed multiplying the storey acceleration by the storey mass and the gravitational acceleration. The inertia force of storey $4, I_{4}$, was, for example, calculated as follows:

$$
I_{4}=-M_{4} \cdot \frac{A c c_{17}+A c c_{18}}{2} \cdot g
$$

where $M_{4}$ is the mass of Storey 4 . The storey masses were computed as the mass of the slab, the mass of the additional masses on the slab and half the mass of the walls above and below the slab; a summary of the storey masses can be found in Table 12. The base shear is the sum of the inertia forces of the four stories (Eq. 2).

Both accelerometers of the fourth storey and one of the accelerometers of the third storey were saturated during the last two tests. Hence, for those tests, it was not possible to derive the inertia forces of the fourth storey and consequently the base shear force. For these last two tests, column 98 of the data file therefore contains "NaN" elements. 
Table 12 Summary of storey masses used for the computation of the base shear force

\begin{tabular}{lr}
\hline Storey 4 & $16.4 \mathrm{t}$ \\
Storey 3 & $17.5 \mathrm{t}$ \\
Storey 2 & $17.5 \mathrm{t}$ \\
Storey 1 & $17.5 \mathrm{t}$ \\
Foundation + shake-table + half mass of first-storey walls & $56.1 \mathrm{t}$ \\
\hline
\end{tabular}

Channel 99 reports a further estimate of the base shear, $V_{b, A C T}$. This second estimate is evaluated as the actuator force of the shake-table, $F_{A C T}$, minus the sum of the inertia force of the shake-table, the inertia force of the foundation and the inertia force of half the mass of the walls of the first storey. The inertia force was obtained by multiplying the acceleration measured by the accelerometer on the shake-table, "Acc_1", by the sum of the masses of the shake-table and the foundation and by the gravitational acceleration (Eq. 1).

A third estimate of the base shear is derived from the recordings of the optical measurement system and is reported in Channel 100. For this method, for each storey, the storey acceleration was computed from the displacement histories of three markers that were connected to the RC slab in correspondence with the central URM wall. These markers correspond to Markers 2.51, 2.54 and 2.57 for the first storey; 1.55, 1.58 and 1.61 for the second storey, 8.64, 8.67 and 8.70 for the third storey and 7.64, 7.67 and 7.70 for the fourth storey. The storey accelerations were obtained by taking the second time derivative of the storey displacements. The noise introduced by this procedure was reduced by applying, after each derivation step, a second-order Butterworth Lowpass filter with a cutoff frequency of $12 \mathrm{~Hz}$. Once the storey accelerations were computed, the base shear, $V_{b, M A R K}$, was evaluated by multiplying the storey acceleration by the storey mass, and finally, the base shear was derived as the sum of the inertia forces at all stories (Eq. 3).

Channel 101 reports the relative top displacement of the structure, $D_{\text {top }}$, with respect to its foundation. This top displacement was evaluated from the recordings of the Optical Measurement System as the difference of the average horizontal displacement of three markers connected to the top slab (Markers 7.64, 7.67 and 7.70) and three markers connected to the foundation (Markers 2.02, 2.05 and 2.08).

Note that all the variables described in this section were computed from the postprocessed database, i.e., after the synchronisation of the conventional and optical measurement systems was performed.

\section{References}

Ambraseys N, Smit P, Sigbjornsson R, Suhadolc P, Margaris B (2002) Internet-site for European strongmotion data. European Commission, Research-Directorate General, Environment and Climate Programme, http://www.isesd.hi.is/

Benedetti D, Carydis P, Pezzoli P (1998) Shaking table tests on 24 simple masonry buildings. Earthq Eng Struct Dyn 27:67-90

Beyer K, Mangalathu S (2014) Numerical study on the force-deformation behaviour of masonry spandrels with arches. J Earthq Eng 18(2):169-186

Beyer K, Petry S, Tondelli M, Paparo A (2014) Towards performance-based design of modern unreinforced masonry structures. In: Theme lecture at the 2nd European conference on earthquake engineering and seismology, Istanbul, Turkey

CEN (2002) EN 1052-1: Methods of test for masonry-part 1: determination of compressive strength. European Committee for Standardisation, Brussels, Belgium 
CEN (2004a) Eurocode 2: design of concrete structures-part 1-1: general rules and rules for buildings EN 1992-1-1. European Committee for Standardisation, Brussels, Belgium

CEN (2004b) Eurocode 8: Design of structures for earthquake resistance_part 1: general rules, seismic actions and rules for buildings. European Code EN 1998-1, European Committee for Standardization, Brussels, Belgium

CEN (2005) Eurocode 8: Design of structures for earthquake resistance — part 3: assessment and retrofitting of buildings, Design Code EN 1998-3. European Committee for Standardisation, Brussels, Belgium

CEN (2007) EN 1052-3: Methods of test for masonry-part 3: determination of initial shear strength. European Committee for Standardisation, Brussels, Belgium

Cervenka J, Papanikolaou VK (2008) Three-dimensional combined fracture-plastic material model for concrete. Int J Plast 24:2192-2220

Cervenka V, Jendele L, Cervenka J (2010) Atena-computer program for nonlinear finite element analysis of reinforced concrete structures. Theory and user manual, Prague, Czech Republic

Chen W (1970) Double punch test for tensile strength of concrete. ACI J 67:993-995

Fajfar P (1999) Capacity spectrum method based on inelastic demand spectra. Earthq Eng Struct Dyn 28:979-993

Freeman SA, Nicoletti JP, Tyrell JV (1975) Evaluations of existing buildings for seismic risk—a case study of Puget Sound Naval Shipyard, Bremerton, Washington. In: Proceedings of the 1st US national conference on earthquake engineering, Oakland, CA, pp 113-122

Giardini D, Wössner J (2012) SHARE: Seismic hazard harmonization in Europe. Final report. http://www. share-eu.org/. Accessed 22 Jan 2014

Grünthal G (1998) European macroseismic scale 1998. Conseil de l'Europe, Cahiers du Centre Européen de Géodynamique et de Séismologie, volume 15, Luxembourg

Haroun MA, Pardoen GC, Bhatia H, Shahi S (1998) Comparative testing of full- and half-scale models of bridge pier walls. In: Proceedings of the 16th international modal analysis conference, Santa Barbara, CA

Jurukovski D, Krstevska L, Alessi R, Diotallevi P, Merli M, Zarri F (1992) Shaking-table tests of three fourstorey brick masonry models: original and strengthened by RC core and by RC jackets. In: Proceedings of the 10th world conference on earthquake engineering, Madrid, Spain

Krawinkler H (1979) Possibilities and limitations of scale-model testing in earthquake engineering. In: Proceedings of the second U.S. national conference on earthquake engineering, Stanford, CA, pp 283-292

Lang K (2002) Seismic vulnerability of existing buildings. Ph.D. thesis, ETH Zurich, Switzerland

Lourenço PB (1996) Computational strategies for masonry structures, Ph.D. thesis. TU Delft, The Netherlands

Lunghi F, Pavese A, Peloso S, Lanese I, Silvestri D (2012) Computer vision system for monitoring in dynamic structural testing. In: Role of seismic testing facilities in performance-based earthquake engineering. SERIES workshop, geotechnical, geological and earthquake engineering, vol 22. Springer, The Netherlands, doi:10.1007/978-94-007-1977-4_9

Ohtaki T (2000) An experimental study on scale effects in shear failure of reinforced concrete columns. In: Proceedings of the 12th world conference on earthquake engineering, Auckland, New Zealand

Paparo A, Beyer K (2014) Quasi-static tests of two mixed, reinforced concrete-unreinforced masonry wall structures. Eng Struct 71:201-211

Petry S, Beyer K (2014a) Scaling unreinforced masonry for reduced-scale seismic testing. Bull Earthq Eng 12(6):2557-2581

Petry S, Beyer K (2014b) Influence of boundary conditions and size effect on the drift capacity of URM walls. Eng Struct 65:76-88

Priestley MJN, Calvi GM, Kowalsky MJ (2007) Displacement-based seismic design of structures. IUSS Press, Pavia

RILEM (1991) RILEM TC 76-LUM: diagonal tensile strength tests of small wall specimens. RILEM Publications SARL

SIA (2003) SIA 261: actions on structures. Swiss Norm, Swiss Society of Engineers and Architects, Zurich Tomaževič M (1999) Earthquake-resistant design of masonry buildings. Imperial College Press, London

Tomaževič M, Modena C, Velechovsky T (1990) Seismic behaviour of mixed structural systems with peripheral masonry walls and internal RC columns: an earthquake simulator study. In: Proceedings of 5th North American masonry conference, Urbana Champaign, USA

Tondelli M, Beyer K (2014) Observations on out-of-plane behaviour of URM walls in buildings with RC slabs. In: Proceedings of the 9th international masonry conference, Guimarães, Portugal 
Tondelli M, Petry S, Beyer K (2013) CoMa WallS—seismic behaviour of mixed reinforced concreteunreinforced masonry wall structures. Final test report, FP7 SERIES-programme, EPFL, Lausanne, Switzerland

UNI (1976) 6556: Tests of concrete-determination of static modulus of elasticity in compression. UNI Standards, Ente Nazionale Italiano di Unificazione, Milan

UNI (1999) EN 1015-11: Methods of test for mortar for masonry-determination of flexural and compressive strength of hardened mortar. UNI Standards, Ente Nazionale Italiano di Unificazione, Milan

UNI (2002) EN ISO 15630-2: steel for reinforcement and pre-stressing of concrete-test methods-part 2: welded fabric. UNI Standards, Ente Nazionale Italiano di Unificazione, Milan

UNI (2003) EN 12390-3: testing hardened concrete-compressive strength of test specimens. UNI Standards, Ente Nazionale Italiano di Unificazione, Milan

UNI (2010) EN ISO 15630-1: Steel for reinforcement and pre-stressing of concrete-test methods-part 1: reinforcing bars, wire rod and wire. UNI Standards, Ente Nazionale Italiano di Unificazione, Milan 